\title{
5. ANALYSE EINES SCHEITERNS
}

In der Einleitung wurde der von Dominique Pestre und Yves Cohen in die technikhistorische Forschung eingebrachte Begriff des »terrains« vorgestellt, der wegen seiner vielfältigen Deutbarkeit und inhaltlichen Offenheit geeignet schien, die in den einzelnen Kapiteln vorgestellten komplexen und verflochtenen Ereignisse, Akteure und Strukturen zu umfassen. In der nun folgenden Analyse des als gescheitert beschriebenen Versuchs, einen einheitlichen europäischen Farbfernsehstandard im Rahmen der CCIR-Tagungen auszuhandeln, wird in einem ersten Schritt danach gefragt, welche Motive oder Gründe für das Scheitern sich in den drei "terrains « finden lassen. Dabei können je nach Perspektive personelle, institutionelle oder strukturelle Motive aufgedeckt und Erklärungsansätze angeboten werden.

Dieser erste Analyseschritt wird als »klassischer « Interpretationsversuch bezeichnet, da sich viele Erklärungen für das Scheitern der Standardisierungsbemühungen aus der Analyse der institutionellen oder strukturellen Kontexte gewinnen lassen, die im Rahmen der drei »terrains« vorgestellt wurden. Wird diese klassische Analyse der mehrdimensionalen Betrachtung des Forschungsgegenstandes gerecht, werden in einem zweiten Analyseschritt alternative Deutungen angeboten, die - so die Hoffnung - Anstöße zu einer kulturgeschichtlichen Interpretation der Farbfernsehkontroverse liefern können. Wie der amerikanische Technikhistoriker Hugh Aitken in seiner Studie zur Entwicklung des Rundfunks in den USA, "The Continuous Wave«, schrieb, finden Standardisierungsprozesse in einer »grey area« statt, »where science, technology, business, and government meet, overlap, and interpenetrate; where resources and information flow between the systems « ${ }^{1}$. Hilfestellung für diese subtilere Interpretation der »grauen Bereiche« der Farbfernsehkontroverse sollen methodische Ansätze aus den Bereichen benachbarter Disziplinen wie der Soziologie, Politikwissenschaft oder der Kulturwissenschaft leisten. Dank ihres anders zugeschnittenen theoretischen Rüstzeuges können sie dazu beitragen, »feine Unterschiede« wahrnehm- und analysierbar zu machen, handlungstheoretische Spielräume zu erschließen und dabei helfen, historisch schwer faßbare Phänomene wie nationale Technikstile oder technopolitische Netzwerke zu interpretieren. Beide Interpretations- und Deutungsangebote zusammengenommen sollen das in der Einleitung formulierte Anliegen legitimieren, diese Studie als einen Beitrag zu einer politischen Kulturgeschichte der Technik zu verstehen.

${ }^{1}$ Hugh Altken, The Continuous Wave: Technology and American Radio (1900-1932), Princeton 1985, S. 22. 


\subsection{Klassische Interpretationsversuche}

Gab es in den drei vorgestellten Bereichen der Technik, Wirtschaft und Politik Hinweise oder gar zwingende Gründe für das Scheitern einer internationalen Übereinkunft über den europäischen Farbfernsehstandard? Um diese Frage zu beantworten, werden im folgenden alle drei »terrains« einer resümierenden Analyse unterzogen.

\subsubsection{Le terrain technique}

Die NTSC-Entwicklung ist zu Recht als technisch-industrielles Gesamtkunstwerk bezeichnet worden, da es den führenden amerikanischen Rundfunkfirmen in erstaunlich kurzer Zeit gelang, die zentralen Probleme des farbigen Fernsehrundfunks zu lösen: 1. die Kompatibilität von Schwarzweiß- und Farbfernsehempfang zu garantieren; 2. die bei der Übertragung farbiger Bilder höhere Informationsdichte ohne Steigerung der Bandbreite und damit Reduzierung der verfügbaren Frequenzen zu realisieren und schlieBlich 3. mit der Lochmaskenröhre das zentrale Bauteil zur Realisierung der vollelektronischen Farbbilderzeugung auf der Empfängerseite zur Verfügung gestellt zu haben. Damit waren in den USA die Weichen für das farbige Fernsehen in einer Zeit gestellt, in der man in Westeuropa gerade erst mit der flächendekkenden Versorgung der Bevölkerung mit $\mathrm{s} / \mathrm{w}$-Fernsehen begann.

Unliebsames Resultat der in der Vorkriegszeit in Europa in rein nationalen Kontexten betriebenen Fernsehentwicklung war, daß es nach 1945 zur Ausbildung unterschiedlicher $s / \mathrm{w}$-Standards in Europa kam. Die unterschiedlichen Zeilennormen machten einen Programmaustausch zwischen den europäischen Ländern zu einem Unterfangen, welches nur unter erheblichem technischen und finanziellen Aufwand realisierbar war. Die Mitte der fünfziger Jahre in Europa beginnende Diskussion um die zukünftige Farbfernsehnorm war aufgrund dieser s/w-Normenvielfalt von Beginn an von dem Wunsch begleitet, die Farbfernsehstandardisierung mit einer Harmonisierung der Zeilennormen zu verbinden. Diese im Rahmen der CCIR zwischen 1956 und 1961 erfolgreich realisierte "Normierung der Grundparameter" war, wie Johannes Müller zu Recht bemerkt, wesentlich wichtiger für die Harmonisierung des internationalen Fernsehrundfunks als die anschließende Wahl des spezifischen Farbfernsehübertragungssystems ${ }^{2}$.

2 Auf der Europäischen Rundfunkkonferenz in Stockholm 1961 wurde diesbezüglich Einigkeit erreicht. "Diese Tatsache«, so Johannes Müller, "wird im allgemeinen nicht hoch genug eingeschätzt, zumal es sich bei solchen Entscheidungen nicht nur um die Lösung eines technischen Problems, sondern um wirtschaftspolitische Entscheidungen handelt, die sich auf die Rundfunkstruktur der davon betroffenen Länder und ihre Fernsehteilnehmer auswirken. Dennoch wurden diese Schwierigkeiten in vorbildlicher Weise auf technischer Ebene gelöst, ohne die Diskussion 
Da die europäischen Systemalternativen SECAM und PAL auf dem amerikanischen NTSC-System aufbauten und daher in wesentlichen Kriterien mit diesem übereinstimmten, war die Debatte um die Validität der europäischen Systemalternativen eher von technisch-industriellen denn von technisch-wissenschaftlichen Gesichtspunkten bestimmt. Die Transcodierbarkeit der Systemalternativen, einer technischen Aufgabe, der man sich unmittelbar nach den gescheiterten Verhandlungen in Oslo in der CCIR-Studiengruppe M (Normwandlung) intensiv zuwandte, sollte bereits kurze Zeit nach der Einführung des Farbfernsehens für einen relativ problemlosen Programmaustausch zwischen Ländern mit unterschiedlichen Farbfernsehsystemen sorgen ${ }^{3}$. Viele von den "Argumenten «, die heutige PAL- oder SECAM-Anhänger zum Beweis der technischen Überlegenheit des einen oder anderen Systems anführen, basieren auf späteren Verfeinerungen der Systemalternativen, die zum Zeitpunkt des Entscheidungsfindungsprozesses im Rahmen der CCIR-Verhandlungen nicht als Erfahrungswissen vorlagen.

Legt man den wissenschaftlich-technischen Kenntnisstand und die produktionstechnischen Erfahrungen als zentrale Bewertungskriterien des damaligen Systemvergleichs zugrunde, so fällt das historisch-kritische Urteil eindeutig aus: Es gab kein »bestes« System. Alle drei Systemalternativen NTSC, PAL und SECAM - sehr wahrscheinlich auch die später in die Diskussion aufgenommene sowjetische NIR-Variante - hätten als Farbfernsehübertragungssysteme einen technisch zufriedenstellenden Farbfernsehbetrieb in Europa sicherstellen können. Eben jene technische Gleichwertigkeit machte eine Entscheidungsfindung aufgrund technischer Argumente extrem schwierig. Obwohl der Wille zur Einigung bei den meisten technischen Experten der CCIR vorhanden war, wurden industrielle und politische Interessen zu den zentralen Entscheidungskriterien. Die Gründe für das Scheitern der Harmonisierungsbemühungen müssen also auf der Ebene der industriellen und politischen Akteure der Farbfernsehkontroverse gesucht werden.

um die technischen Erfordemisse durch politische Akzente zu belasten«. MüLLER, Die internationalen Bemuihungen um eine europäische Farbfernsehnorm, S. 249.

3 Johannes Müller beschreibt die Vorteile der Transcodierung im Vergleich zur früher notwendigen Zeilenumwandlung sehr anschaulich: »Das Problem der Transcodierung ist deshalb einfacher zu lösen als das einer Normwandlung von Bildern unterschiedlicher Zeilenzahl, weil lediglich die Farbinformation am oberen Bandende des Kanals von einem Modulationsverfahren in das andere überführt werden muB, während das Schwarzweißbild beibehalten werden kann«, in: ibid. S. 250. $\mathrm{Zu}$ den Problemen der Transcodierung siehe Walter BRUCH, Transcodierung - Farbsignalwandlung. Die Wandlung von Farbfernsehsignalen eines Verfahrens in die eines anderen, in: Jahrbuch des elektrischen Fernmeldewesens 20 (1969) S. 252-280; F. JAESCHKE, H. WENDT, Ein Transcoder zur Umsetzung von SECAM in PAL-Systemen, in: Radio Mentor (1968) 7 S. 494-498; Howard F. STEELE, The Transcoding of Colour Television Signals, in: The Television Society Journal 11 (1965) 2 S. 28-33. 


\subsubsection{Le terrain industriel}

Als im Jahre 1953 in den USA das NTSC-Farbfernsehsystem eingeführt wurde, war die europäische Rundfunkindustrie damit beschäftigt, den s/w-Fernsehmarkt aufzubauen. Obwohl Großbritannien und Frankreich relativ zügig nach Kriegsende mit der Ausstrahlung eines mehr oder weniger regelmäßigen Fernsehprogramms begannen, fand - mit Ausnahme Großbritanniens der industrielle »take off " des Fernsehsektors erst in der zweiten Hälfte der fünfziger Jahre statt. Selbst das s/w-Fernsehgerät blieb bis Ende der siebziger Jahre ein ausgesprochenes Luxusgut. Der Wandel des Farbempfängers zum industriellen Konsumgut fand in Europa erst in den achtziger Jahren statt. Mit entsprechender Verzögerung setzte man sich auf seiten der europäischen Rundfunkindustrie ernsthaft mit dem Thema Farbfernsehen auseinander. Die farbfernsehtechnischen Aktivitäten einiger weniger Rundfunkfirmen konnten jedoch - wie im Falle der CFT oder Telefunkens geschehen - zu wichtigen Weiterentwicklungen des amerikanischen Systems führen. Für die meisten großen Rundfunkunternehmen (Thorn, Mullard, Philips, Grundig) blieb das amerikanische System aufgrund der langjährigen Fertigungserfahrung das Referenzsystem, mit dessen Einführung man bis Anfang der sechziger Jahren in den meisten europäischen Ländern fest rechnete.

Mit dem Erscheinen des von Henri de France entwickelten SECAM-Systems im Jahre 1956 und dem vom Telefunken-Ingenieur Walter Bruch entwickelten PAL-System im Januar 1963 kam es zu einer ernsthaften Konkurrenz für das amerikanische Verfahren. Da sich im Laufe der Untersuchungen der EBU ad-hoc-Kommission für das Farbfernsehen die technische Gleichwertigkeit beider NTSC-Weiterentwicklungen im Vergleich mit dem amerikanischen "Muttersystem " zeigte, witterte man sowohl bei der CFT als auch bei Telefunken die Chance, das jeweilige System als europäische Alternative zum NTSC-System durchsetzen zu können. Beide Seiten wußten, daß sie im Falle der Einführung ihres Systems mit enormen Lizenzeinnahmen rechnen konnten. Wie die folgende Grafik zeigt, schätzte man bei Telefunken, daß die jährlichen Lizenzeinnahmen für die PAL-Patente bis auf sechs Millionen DM im Jahr 1974 ansteigen könnten.

Die zu erwartenden Lizenzeinnahmen erklären das unternehmerische Engagement, mit dem sowohl die CFT als auch Telefunken seine Interessen in den Farbfernsehverhandlungen vertrat. War das Ziel auf französischer wie auf deutscher Seite identisch, unterschieden sich die industriepolitischen Strategien beider Akteure sehr deutlich. Während der CSF-Vorstandsvorsitzende Maurice Ponte gemäß der französischen Tradition die Unterstützung der Politik suchte, kam es auf bundesdeutscher Seite zu unternehmerischen Aktivitäten, um die englische und niederländische Rundfunkindustrie für das PAL-System zu gewinnen. Beide Strategien sollten sich letztlich als erfolg- 
Abb. 26: Erwartete PAL-Lizenzeinnahmen bei Telefunken, aus: AEG-Telefunken-Archiv, Deutsches Technikmuseum Berlin, Signatur GS 1648.

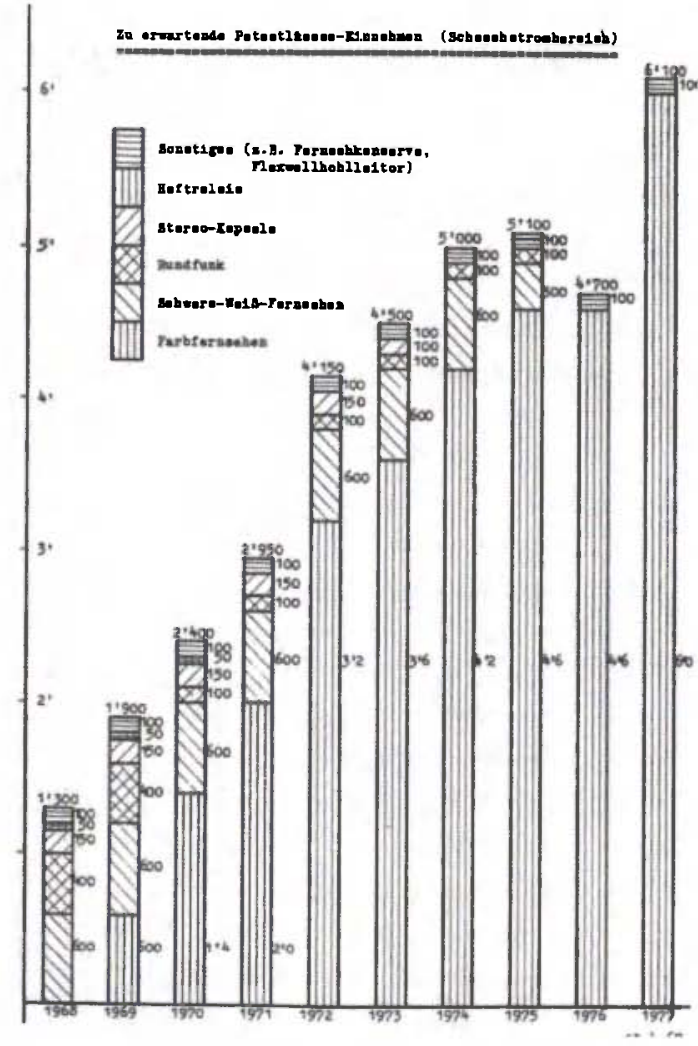

reich herausstellen und aus diesem Grunde eine einheitliche Lösung in Europa unmöglich machen.

Sowohl in Frankreich als auch in der Bundesrepublik dominierten bereits vor der entscheidenden CCIR-Konferenz in Oslo die industriellen Interessen die Handlungsoptionen der verhandelnden Akteure. Auf deutscher (Telefunken) wie auf französischer (CFT) Seite war man sich darüber im klaren, daB beide Seiten im Falle einer Verhinderung eines einheitlichen Systems als Gewinner hervorgehen würden. Dementsprechend gering war das Interesse beider Firmen, in Oslo das als potentielle europäische Alternative in die Debatte eingebrachte NIR-System in irgendeiner Weise zu unterstützen. Zwar hätte die CFT weiterhin mit entsprechenden Lizenzeinnahmen rechnen können, doch gefährdete eine solche Einigung die Handelsinteressen der CSF, die sich von der französisch-sowjetischen Kooperation einseitige Absatzmärkte erhoffte. Im Falle der Durchsetzung des NIR-Systems hätten sowjetische Stellen mit Sicherheit auf eine entsprechende Beteiligung an der internationalen Vermarktung gepocht. Bei der alleinigen patentrechtlichen Verfügung der CFT über das SECAM Ill-System waren entsprechende Forderungen leicht 
abzuweisen. Für Telefunken war die Situation noch prekärer: Eine europäische Einigung zugunsten des NIR-Systems hätte sämtliche Lizenzforderungen Telefunkens zunichte gemacht. Nicht zuletzt hätte eine solche Einigung bedeutet, daB die Erfindervergütungen, die einige an der Entwicklung des SECAM- wie auch des PAL-Systems beteiligte Ingenieure zu erwarten hatten, entweder ganz weggefallen oder wesentlich geringer ausgefallen wären ${ }^{4}$.

Mit der in Oslo erreichten PAL-SECAM-Spaltung konnten demnach sowohl die französischen als auch die bundesdeutschen Patentinhaber gut leben. Zudem stellte die erreichte Lösung für die europäische Rundfunkindustrie insgesamt einen gewissen Schutz vor der übermächtigen amerikanischen und der expandierenden japanischen Farbfernsehindustrie dar. Die Übernahme des NTSC-Systems, obwohl anfänglich von den mächtigen britischen und niederländischen Rundfunkherstellern aus Exportgründen gefordert, hätte vor allem die zahlreichen mittelgroßen Fernsehgerätehersteller unter enormen Kostendruck gesetzt. Mit ziemlicher Sicherheit hätte diese Konkurrenzsituation das große Firmensterben, welches Ende der siebziger, Anfang der achtziger Jahre besonders in der bundesrepublikanischen Firmenlandschaft grassierte, deutlich früher einsetzen lassen.

Schließlich sorgte auch der zwischen AEG-Telefunken und der CFT im Jahre 1968 geschlossene »Nichtangriffspakt «, der die Streitigkeiten zwischen beiden Unternehmen bezüglich der Patentabhängigkeit des PAL-Systems von SECAM beilegte, zu einer für beide Seiten profitablen Einigung. In der Presseinformation, die Telefunken anläBlich der Unterzeichnung des Abkommens veröffentlichte, war von der jahrelang schwelenden Patentauseinandersetzung keine Spur mehr zu erkennen. Die Einigung wurde gar als weiterer Beitrag zur deutsch-französischen Annäherung verkauft:

Die Compagnie Française de Télévision CFT (Paris), als Urheber des SECAM-Farbfernsehsystems, und die Allgemeine Elektrizitätsgesellschaft AEG-Telefunken (Berlin/Frankfurt), als Urheber des PAL-Systems, haben sich im Sinne einer französisch-deutschen Zusammenarbeit in freundschaftlicher Weise auf dem Patentgebiet miteinander verständigt. Beide Unternehmen verzichten gegenseitig auf Angriffe gegen ihre Schutzrechte: CFT stellt der deutschen Industrie eine Lizenz für SECAM-Empfänger sowie eine Nichtangriffszusage in bezug auf PAL-Empfänger zur Verfügung und umgekehrt AEG-Telefunken der französischen Industrie eine Lizenz für PAL-

4 Aus dieser Perspektive wohlbegründet waren die schmeichelnden Dankesworte, die Walter Bruch im Anschluß an die Osloer Konferenz an den deutschen Delegationsleiter Hans Pressler richtete: „Lieber Herr Pressler, Thre feste und aufrichtige Haltung schon in Wien und jetzt in Oslo zusammen mit Threm Kollegen aus England wird bestimmt in die Geschichte des Farbfernsehens eingehen. Es muß Ihnen doch eine besondere Freude bereitet haben, jetzt von einer höheren Warte aktiv auf einem Gebiet zu wirken, auf dem Sie mit als erster in Deutschland vor etwa 30 Jahren schon als Entwicklungs- und Forschungsingenieur gearbeitet haben «. Brief von Walter Bruch an Hans Pressler, 10.08.1966, in: Archiv des Deutschen Museum München, Nachlaß Walter Bruch, Signanur NL 101, Nr. 202. 
Empfänger. Die gegenseitige Lizenzbereitschaft umfaßt auch kombinierte PAL-SECAM-Empfänger 5 .

Nur aufmerksame Leser werden dieser Pressemitteilung damals entnommen haben, daß nur die CFT den potentiellen PAL-Produzenten eine Nichtangriffszusage zusagte. Konkret bedeutete dies, daß die CFT auf die patentrechtliche Auseinandersetzung verzichtete, dieser Verzicht aber mit einer Nichtangriffsgebühr verbunden war, welche alle PAL-Produzenten an die CFT zu zahlen hatten ${ }^{6}$. In der Tat bedeutet dieser »Nichtangriffspakt « eine Absicherung AEG-Telefunkens vor eventuellen patentrechtlichen Auseinandersetzungen, da man sich in der Patentabteilung von Telefunken nicht sicher war, die Unabhängigkeit des PAL-Systems von SECAM-Patenten im Falle einer juristischen Auseinandersetzung nachweisen zu können. Für die CFT stellte sich dieses Abkommen in den Folgejahren als überaus gutes Geschäft dar, da sie an jedem verkauften Gerät des Konkurrenten mitverdiente ${ }^{7}$ !

Erstaunlich ist die Tatsache, daß sich weder die amerikanische Politik noch amerikanische Unternehmen stärker in die europäische Farbfernsehdebatte eingeschaltet haben. Wie am Beispiel der NTSC-Werbemission von RCA-Chefentwickler Brown in Moskau 1965 aufgezeigt wurde, war die sehr restriktive Außenhandelspolitik der USA gegenüber den Ostblockstaaten (Stichwort COCOM) ein ernsthaftes Hindernis für den West/Ost-Techniktransfer. Allerdings erklärt dies nicht die Zurückhaltung gegenüber den westeuropäischen Staaten. An dieser Stelle können nur Vermutungen über die amerikanische Zurückhaltung angestellt werden. Zwei Umstände bieten sich als Erklärung an. Zum einen baute sowohl das SECAM- als auch das PALSystem auf dem amerikanischen NTSC-System auf, was bedeutete, daß die europäischen PAL- oder SECAM-Hersteller weiterhin Lizenzgebühren an die

${ }^{5}$ Presse-Information (pri 513), Frankfurt a. M., 27.03.1968, in: AEG-Telefunken-Archiv, Deutsches Technikmuseum Berlin, Signatur GS 1648.

${ }^{6}$ Der Wortlaut der Vereinbarung zwischen der CFT und AEG-Telefunken vom Februar 1968 legte fest, daß die CFT darauf verzichtet, gegen Hersteller, Verkäufer und Benutzer von PAL Empfängern mit Laufzeitdecoder auf dem Prozeßwege vorzugehen und der einschlägigen Industrie für PAL-Empfänger eine Nichtangriffserklärung unter ihren Schutzrechten jeweils für die Laufdauer des französischen Patents »1 327060« (G. Melchior, Priorität: 2.3. 1962) nach den in dem betreffenden Land entsprechenden Schutzrechten zur Verfügung zu stellen. Der Verzicht war gebunden an eine Nichtangriffsgebühr. Diese betrug 0,25\% des PAL-Empfängerpreises ab Werk. Siehe die zahlreichen Verhandlungsprotokolle im AEG-Telefunken-Archiv, Deutsches Technikmuseum Berlin, Signatur GS 1648 sowie entsprechende Unterlagen in den Archives du MAE, Affaires Économiques et Financières, Affaires Générales, Nr. 926 und die CFT-Unterlagen in den Archives du CHTV/INA, Nachlaß M. Dubail.

${ }^{7}$ Der ehemalige CFT-Direktor Michel Dubail wies im Interview mit dem Autor mehrfach darauf hin, dab sich die Subventionen des französischen Staates in das SECAM-System aus diesem Grunde auch für den Staat bezahlt gemacht hätten, da diese - wie vereinbart und im Falle von SECAM geschehen - bei entsprechend erfolgreichen Geschäften an den Staat zuriickgezahlt wurden. 
Inhaber der zentralen NTSC-Patente (vor allem Hazeltine und RCA) zahlen mußten. Zum anderen besaßen amerikanische Unternehmen, allen voran die RCA, die Patente als auch das zentrale Produktionswissen zur Herstellung des Kernstücks des Farbempfängers, der Farbfernsehröhre. Ohne vertraglich festgelegte Abkommen mit der RCA war es für europäische Firmen unmöglich, an Lizenzen sowie das wichtige Produktionswissen heranzukommen.

Die absolute Vormachtstellung der RCA auf dem Farbfernsehröhrengebiet wird deutlich, wenn man sich die amerikanischen Verkaufszahlen vor Augen führt. Von 1955 bis 1962 investierte die RCA rund 130 Millionen Dollar in die Fertigungstechnik der shadow-mask-Farbbildröhre. Es verwundert daher nicht, daß das Farbempfängergeschäft in den USA bis 1962 ein Verlustgeschäft blieb. Ab 1962 stieg der Verkauf von Farbgeräten in den USA jedoch steil an, so daß die RCA Schwierigkeiten hatte, den amerikanischen Farbfernsehempfängermarkt mit Farbröhren zu versorgen. Erst 1964 begannen andere Firmen wie Zenith, Motorola, Sylvania, General Electric und Admiral mit der Lizenzproduktion von Farbröhren. Dennoch blieb die RCA mit Abstand wichtigster Röhrenproduzent. 1965 teilte die Geschäftsleitung der RCA den anderen amerikanischen Geräteherstellern mit, daß sie den Röhrenverkauf an andere Firmen reduzieren müsse, um den eigenen Bedarf sättigen zu können ${ }^{8}$.

Ein weiterer Grund, weshalb sich die amerikanischen Firmen nur wenig mit der europäischen Situation beschäftigt haben dürften, könnte der Umstand gewesen sein, daß nicht die Europäer sondern die Japaner als gefährliche Konkurrenten der amerikanischen Industrie angesehen wurden. Der Einbruch der japanischen Hersteller in den amerikanischen Markt sollte die amerikanische Rundfunkindustrie in den siebziger Jahren in eine ernste Krise stürzen. Zwischen 1971 und 1979 reduzierte sich die Zahl der amerikanischen Fernsehgerätehersteller von 20 auf 5 Firmen, über 60000 Arbeitsplätze gingen in dieser Branche verloren ${ }^{9}$. In den USA führte diese $»$ japanische Invasion «, die durch den Einzug billiger, transportabler s/w-Geräte eingeleitet worden war, Ende der siebziger Jahre zu einer intensiven Diskussion über die möglichen Vorzüge einer sektoriellen Industriepolitik mit protektionistischen Elementen gegenüber der bis dato sehr liberalen Wirtschaftspolitik. Die Dissertationen von Vincent A. Lafrance »The United States Television Receiver Industry: United States versus Japan, 1960-1980« und James Howard Wooster »Industrial Policy and International Competitiveness: A Case

8 Siehe hierzu die von der Außenhandelsabteilung des ZVEI im November 1965 veröffentlichte Studie $» D i e$ elektrotechnische Industrie der Welt: Das Farbfernsehen $\ll$, in der die amerikanische und japanische Situation mit viel Zahlenmaterial dargestellt wird. In: Archiv des Deutschen Museums München, Nachlaß Walter Bruch, Signatur NL 101, Nr. 202.

${ }^{9}$ Ronald I. MeTzLer, Color-TV Sets and U.S.-Japanese Relations: Problems of Trade-Adjustment Policymaking, in: Orbis Philadelphia 23 (1979) 2 S. 421-446. 
Study of U.S.-Japanese Competition in the Television Receiver Manufacturing Industry« kommen beide zu sehr ähnlichen Einschätzungen diesbezüglich $^{10}$. Bei Wooster heißt es:

Many believe that the adoption of industrial policies by other countries is directly related to the U.S. decline in the first set of industries and threatens the dominance or even the continued viability of U.S. firms in the second set of industries. This work supports that view by showing that conscious industrial policy in Japan and de facto industrial policy in the U.S. contributed to the decline of one industry in the U.S., the television receiver manufacturing industry ${ }^{11}$.

Während Woosters Arbeit stärker die industriepolitischen Aspekte der amerikanisch-japanischen Konkurrenz herausarbeitet, konzentriert sich Lafrances' Arbeit auf produktionstechnische (vertikale Integration, Automatisierung, R\&D-Investitionen, Arbeitsteilung, Management, Produktionszyklen) oder wirtschaftspolitische (Lohnkosten, Zölle) Faktoren. Interessant ist die Anmerkung von Lafrance, daß die vom Staat eingeforderte offene Lizenzpolitik der RCA die japanische Konkurrenz stark gefördert hat, während beispielsweise AEG-Telefunken den Japanern die PAL-Lizenzen längere Zeit verweigert hat und anschließend genaue Marktaufteilungen vereinbarte ${ }^{12}$. Diese eher protektionistische Lizenzpolitik hat den Einzug japanischer Produkte in Europa zwar nicht verhindert, aber dennoch verzögert. Dafür war der anschließende Einbruch umso massiver. Die frühe japanische Konkurrenz hat bei amerikanischen Firmen eher zu einem Konzentrationsprozeß geführt, und sie dadurch auf lange Sicht konkurrenzfähiger als die europäischen Unternehmen gemacht. Die beiden Argumente, die zu erwartenden Lizenzeinnahmen in Europa sowie die japanische Konkurrenz im Inland, können nur als Vermutung für die Zurückhaltung der Amerikaner in der europäischen Farbfernsehdiskussion angeführt werden.

Nach diesem kurzen Exkurs in die amerikanische Rundfunklandschaft können die aus industrieller und wirtschaftspolitischer Perspektive eindeutigen Gründe für das Scheitern der Standardisierungsbemühungen wie folgt zusammengefaßt werden:

1. Sowohl die CFT als auch Telefunken waren aus lizenzpolitischen Gründen an der Verhinderung einer europäischen Einigung - die in Oslo nur NIR hätte lauten können - interessiert. Für beide Seiten war eine Spaltung Europas, das heißt die Einführung beider Systeme, die profitablere Alternative.

2. In Oslo drängten sowohl die englische als auch die bundesdeutsche Rundfunkindustrie auf die Beibehaltung des geplanten Einführungstermins

${ }^{10}$ Beide Dissertationen wurden in einem Abstand von nur wenigen Monaten an der Pennsylvania State University (Lafrance, August 1985) bzw. der University of Massachusetts (Wooster, Februar 1986) eingereicht.

11 Wooster, Industrial Policy and International Competitiveness, S. 494.

12 Lafrance, The United States Receiver Industry, S. 472-480. 
eines regelmäßigen Farbfernsehbetriebs im Herbst 1967. In beiden Ländern erhoffte man sich von der Einführung des Farbfernsehens positive Impulse für das Fernsehgeschäft, nachdem sich im s/w-Geschäft eine erste Marktsättigung ankündigte. Anders als in den USA wurde dieser Absatzrückgang in Europa nicht durch einen Trend zum tragbaren Zweit- oder gar Drittgerät aufgefangen.

3. Im Gegensatz zu den nationalen Rundfunkanstalten, die in ihrer täglichen Praxis unmittelbar mit den Folgen unterschiedlicher Systemstandards konfrontiert sein würden und sich bis zum Schluß vehement für eine einheitliche europäische Lösung stark machten, wurde die Industrie von einer europäischen Spaltung nicht in Mitleidenschaft gezogen. Vielmehr bedeutete das Osloer Verhandlungsresultat, $\mathrm{da} B$ die Industrie - wie schon bei den s/w-Empfängern - Mehrnormengeräte auf den Markt bringen würde. Die Mehrkosten dieser aufwendigeren Technik hatte jedoch der Fernsehzuschauer (d.h. der potentielle Käufer eines Farbfernsehgerätes) zu zahlen, nicht die Geräteindustrie. Für spezialisierte Hersteller bedeutete der Verkauf von entsprechenden Transcodern sogar ein zusätzliches Geschäft.

\subsubsection{Le terrain politique}

In Frankreich griff der Staat gemäß des vorgestellten Modells der Vernetzung industrieller und politischer Entscheidungswege auf mehreren Ebenen in die Promotion des SECAM-Systems ein. Mit der Benennung von François de Laboulaye zum »Délégué interministériel« wählte der französische Staat eine Strategie industriepolitischer Steuerung, die direkte Subventionen, langfristige Kreditvergaben und personalpolitische Mittel als dirigistische Instrumente einsetzte. Obwohl der CSF bereits 1965 ein Kredit in Höhe von 70 Millionen französischen Francs zur Finanzierung der SECAM-Entwicklung und Werbung gewährt worden war, zudem der Haushalt der ORTF für die Jahre 1965 und 1966 um jeweils 15 Millionen Francs aufgestockt worden war, begann die in Frankreich als »la bataille du SECAM« bezeichnete aggressive SECAM-Propagation erst nach Oslo ${ }^{13}$.

In der Bundesrepublik fand Telefunken zwar im Bundespost- sowie Bundeswirtschaftsministerium Unterstützer der PAL-Technologie, doch blieb Telefunken eine offizielle politische Fürsprache seitens des Bundespresse- und

${ }^{13} \mathrm{Zu}$ den finanziellen Unterstützungen siehe den Brief von Jean-Jacques de Bresson an Burin de Roziers, Secrétaire Général de la Présidence de la République, Paris, 8.10.1965. In diesem Brief informiert de Bresson Burin de Roziers über die finanzpolitischen Anstrengungen zur Propagation des SECAM-Systems. In: Archives du MAE, Affaires Economiques et Financières, Affaires Générales, Nr. 220c. Zu den SECAM-Werbeaktionen unter Staatspräsident Georges Pompidou siehe ausführlich Fickers, "Pourqui ne feraient-ils pas un procès à Telefunken? . 
Informationsamtes lange Zeit verwehrt. Erst nach dem auch in Bonn als Affront empfundenen französisch-sowjetischen Farbfernsehabkommen gab Staatssekretär Karl-Günther von Hase seinen pro-französischen Kurs zugunsten einer deutsch-englischen Annäherung auf. Allerdings achtete man bei öffentlichen Stellungnahmen darauf, technisch-wissenschaftliche Aussagen in den Vordergrund der Argumentation zu stellen. Der offenen Politisierung der Farbfernsehfrage von seiten der Franzosen begegnete man in der Bundesrepublik mit einer bewußten »Entpolitisierungsstrategie«, die darauf abzielte, das PAL-System als technisch »bestes« System zu propagieren.

Auch nach Oslo sollte die Bundesregierung AEG-Telefunken nur in einem einzigen Falle finanziell unter die Arme greifen, im Falle der PAL-Werbung in Brasilien ${ }^{14}$. Die französischen Werbeaktionen für SECAM dagegen konnten, wie das Beispiel Italiens zeigt, bis hart an die Grenze legaler Unternehmungen herangehen. So versuchte man 1969, den Einfluß des FIAT-Chefs Agnelli für die SECAM-Sache zu gewinnen, in dem man ihm eine entsprechende Beteiligung beim französischen Automobilkonzern Citroën in Aussicht stellte ${ }^{15} .1970$ ging das zwei Jahre zuvor neugegründete SECAM-Werbeunternehmen INTERSECAM noch einen Schritt weiter, in dem man sowohl die Parteikasse der Democratia Christiana (DC) als auch die der Partito Socialista Italiana (PSI) durch Spenden aufbesserte ${ }^{16}$ ! Allerdings sollte sich die französische Finanzspritze als Fehlinvestition herausstellen, da Italien im August 1975 das PAL-System einführte ${ }^{17}$.

Auch auf dem "terrain politique" standen demnach die Karten für eine europäische Einigung nicht gut. Potentielle Gründe für ein Scheitern gab es zahlreiche:

1. Sah es zu Beginn der europäischen Farbfernsehdebatte danach aus, als könnte es im Rahmen der deutsch-französischen Annäherung zu einer gemeinsamen Haltung in der Systemfrage kommen, scheiterten diese Bemühungen aus französischer Sicht aufgrund der mangelhaften Kooperationsbereitschaft seitens der Bundesrepublik. Kooperationsbereitschaft bedeutete in diesem Fall, daß der Leiter des Bundespresse- und Informationsamtes willens und in der Lage war, die deutsche Rundfunkindustrie zur Übernahme

14 Protokoll der Besprechung Herriger/Zickermann mit Bundesfinanzminister Strauß in Bonn am 1.8. 1967. Dort heißt es: »Mit Rücksicht auf politische und taktische Gründe sollten die FörderungsmaBnahmen der Regierung vertraulich behandelt werden und so wenig wie möglich nach außen überhaupt nicht - erwähnt werden«, in: AEG-Telefunken-Archiv, Deutsches Technikmuseum Berlin, Signatur GS 1646.

15 Siehe Akten zur Auswärtigen Politik der Bundesrepublik Deutschland, 1969, Bd. 1, Dok. 83, S. 293-296.

16 Akten zur Auswärtigen Politik der Bundesrepublik Deutschland, 1970, Bd. 2, Dok. 265, S. 973-975.

17 Siehe Fickers, »Pourquoi ne feraient-ils pas un procès à Telefunken?« 
des SECAM-Systems zu bewegen. Während der Wille zur Einigung selbst nach dem Wechsel von Adenauer zu Erhard durchaus das Leitmotiv der Handlungen Karl-Günther von Hases blieb, war sein Einfluß auf die Landesrundfunkanstalten wie auf die Rundfunkindustrie sehr beschränkt. Eine Einigung im Rahmen der deutsch-französischen Konsultationsgespräche war damit bereits Mitte des Jahres 1964 nicht mehr zu erwarten, da sich die mächtige deutsche Rundfunkindustrie (ZVEI) hinter das PAL-System gestellt hatte.

2. Im Gegensatz zur Bundesrepublik genoß das Thema Farbfernsehen in Frankreich oberste politische Priorität und wurde vom französischen Staatspräsidenten Charles de Gaulle zum Paradeobjekt des französischen Modernisierungsprozesses (Stichwort »champion national«) und zum Symbol eines europapolitischen Kurswechsels erhoben. Als »Concorde franco-russe« sollte das SECAM-System zum farbigen Symbol einer neuen Ära französisch-sowjetischer Beziehungen werden und beide Länder im Rahmen eines technisch-industriellen Kooperationsabkommens einander näherbringen.

c) Mit diesem außenpolitischen Kurswechsel verband sich ein industriepolitisches Kalkül, das der Technische Berater im Kabinett von Alain Peyrefitte, Philippe Olivier, im September 1965 wie folgt zusammenfaßte:

Le manovre français était à quadruple détente. Il s'agissait, dans un premier temps, de lier l'URSS au procédé SECAM, ce qui aurait pour effet, dans un second temps, de faire basculer à leur tour les pays du camp socialiste parmi lesquels l'Allemagne de l'Est, dont le choix, dans un troisième temps, entraînerait, du moins pouvait-on l'espérer, celui de l'Allemagne Fédérale, consacrant ainsi, dans un quatrième temps, l'effondrement ou tout au moins la désagrégation du camp du PAL et en tous les cas l'élimination définitive du NTSC américain. Jusqu'à la fin de la conférence de Vienne, les deux premières phases de la manœuvre se sont déroulées >conformément au plan établi<. [...] Mais, dès la réunion de Vienne, la troisième phase de la manœuvre française a échoué. [...] Il s'avère à présent, ou ce n'est qu'une question de jours, que la quatrième phase de la manœuvre française a elle aussi échoué. Non seulement aucune défection n'a été enregistrée dans le camp du PAL, mais encore celui-ci va-t-il se trouver considerablement renforcé par l'adhésion désormais prochaine, de la Grande Bretagne et des Pays-Bas, désertant définitivement le camp aux démeurant déjà presque désert du NTSC américain, lequel fait de toute matière les frais de l'opération ${ }^{18}$.

Olivier schätzte die zukünftige Entwicklung in seiner Betrachtung ganz richtig ein, denn statt des erhofften »Überlaufens« der Bundesrepublik zum französischen SECAM-Ufer kam es in Oslo zu der vorhergesagten deutsch-britisch-niederländischen PAL-Achse, die das endgültige Scheitern eines europäischen Kompromisses besiegelte.

Faßt man die bislang angeführten Gründe für ein Scheitern des Standardisierungsprozesses zusammen, so dominieren auf seiten des »terrain indu-

18 Philippe Olivier, Note sur la télévision en couleurs, Paris, 2.09.1965, 21 maschinegeschriebene Seiten, hier S. 14, in: Archives du MAE, Affaires Économiques et Financières, Affaires Générales, Nr. 220c. 
striel« die lizenzpolitischen Überlegungen der beteiligten Akteure, während es auf Seiten des »terrain politique « außen- und industriepolitische Strategien waren. Lediglich auf der Ebene des "terrain technique « konnte bei einigen Akteuren, vor allem bei den Ingenieuren der nationalen Rundfunkorganisationen, ein echter Wille zur Harmonisierung der Farbfernsehnorm in Europa festgestellt werden. 


\subsection{Ergänzende Interpretationsangebote}

Kann das Scheitern der Standardisierungsbemühungen anhand klassischer wirtschafts- und politikhistorischer Ansätze analysiert und erklärt werden, zeichnen sich neuere Arbeiten in der Technikgeschichtsschreibung dadurch aus, $\mathrm{da} B$ sie ergänzende methodische Herangehensweisen oder Fragestellungen in ihre Darstellungen und Interpretationen technischer Artefakte oder Innovationen aufnehmen. Diese neueren Ansätze der Technikgeschichtsschreibung sind darum bemüht, frühere Interpretationen der Geschichte technischer Entwicklungen zu revidieren, die stark an deterministischen Fortschrittsmodellen angelehnt waren ${ }^{19}$. Zwar sind sich ältere und neuere Ansätze darin einig, daß »technology « einen prominenten Platz im Prozeß der Modernisierung einnimmt, doch wird Technik und Technologie nicht mehr als ein von der Umwelt unbeeinflußter und autonom agierender Agent technischen Wandels begriffen ${ }^{20}$.

Zwar hatten schon Autoren wie Marc Bloch ${ }^{21}$ oder Bertrand Gille ${ }^{22}$ in ihren wegweisenden Arbeiten zur mittelalterlichen und fruihneuzeitlichen Technikgeschichte auf die Komplexität technischer Innovationsprozesse hingewiesen und für die Aufnahme sozialpsychologischer oder systemtheoretischer Fragestellungen plädiert, doch setzten sich erst in den siebziger Jahren verstärkt wissenssoziologisch oder systemtheoretisch inspirierte Ansätze als »legitime « methodologische Herangehensweisen durch. Folgenreich für die angloamerikanische und zunehmend auch europäische Technikgeschichtsschreibung waren die Arbeiten des amerikanischen Technikhistorikers Thomas P. Hughes, der die systemtheoretischen Ansätze aus dem Bereich der Geistesund Ingenieurwissenschaft kombinierte und zu seinem Konzept der »large

19 Siehe beispielhaft hierzu die Beiträge in dem Sammelband von Merritt RoE SMITH, Leo MarX (Hg.), Does Technology Drive History? The Dilemma of Technological Determinism, Cambrigde, London 1998. Einen lesenswerten Überblick über neuere, dem kulturgeschichtlichen Ansatz näherstehende Publikationen im Bereich der Wissenschafts- und Technikgeschichte bietet Mikael HÅRD, Zur Kulturgeschichte der Naturwissenschaft, Technik und Medizin. Eine internationale Literaturibersicht, in: Technikgeschichte 70 (2003) 1 S. 23-45.

20 Wie wirkungsmächtig und wie tief verankert diese deterministische Deutung der Technik auch in gesellschaftlichen oder politischen Strukturen ist, hat Otto Mayr für die Frühe Neuzeit in seinem anregenden Buch »Uhrwerk und Waage« überzeugend geschildert. Siehe Otto MaYR, Uhrwerk und Waage. Autorität, Freiheit und technische Systeme in der frühen Neuzeit, München 1983.

${ }^{21}$ Siehe die in den »Mélanges historiques« versammelten Aufsätze von Bloch zur Wassermühle und den sozialpsychologischen und mentalitätshistorischen Herausforderungen, welche die technischen Innovationen für das Mittelalter bedeuteten. Мarc ВLOCH, Mélanges historiques, Bd. 2, Paris 1963, S. 791-838.

22 Bertrand Gille (Hg.), Histoire des techniques: technique et civilisations, technique et sciences, Paris 1978; DeRs., Les ingénieurs de la renaissance, Paris 1978. 
technological systems« ausbaute ${ }^{23}$. Einen ähnlichen Ansatz verfolgte in Frankreich der Techniksoziologe Michel Callon, der statt von »large technological systems « lieber von »Akteur-Netzwerken« sprach, um die Offenheit technischer Systeme zu betonen ${ }^{24}$. Dieser Ansatz wurde in Deutschland vor allem von Renate Mayntz und Mitarbeitern am Max-Planck-Institut für Gesellschaftsforschung in Köln zum sogenannten Modell des »akteurzentrierten Institutionalismus« weiterentwickelt und speziell zur Untersuchung von Standardisierungsprozessen benutzt ${ }^{25}$. Eine Art »Zusammenschau « diverser netzwerk- und handlungstheoretischer Ansätze aus soziologischer Perspektive liefert der französische Soziologe Alain Gras in seinem Buch »Grandeur et dépendance ${ }^{26}$.

In den achtziger und neunziger Jahren wurde die technikhistorische »Community« vor allen Dingen durch die Diskussion wissenssoziologischer Ansätze angeregt. Resultat dieses Diskurses, der durchweg von kontroversen Positionskämpfen um die »Deutungsmacht« begleitet war, war eine sozialkonstruktivistische Wende der angloamerikanischen Technikgeschichts-

23 Thomas P. Hughes, Networks of Power: Electrification in Westem Society, 1880-1930, Baltimore 1983; DERS., The Evolution of Large Technological Systems, in: Wiebe E. BuJKER, Thomas P. Hughes, Trevor PINCH (Hg.), The Social Construction of Technological Systems. New Directions in the Sociology and History of Technology, Cambridge, London 1987, S. 51-82. Eine Aufsatzsammlung mit Fallstudien zur amerikanischen, französischen und deutschen Technikgeschichte, vor allem im Bereich Transport- und Kommunikationstechnik (Eisenbahn und Telefon), liefert der Sammelband von Renate MaYnTz, Thomas P. Hughes (Hg.), The Development of Large Technical Systems, Frankfurt a.M. u. a. 1988. Eine allgemeinverständliche Einleitung in das Thema Kultur und Technik, in der der Systemcharakter der Technik eine bedeutende Rolle spielt, bietet Hughes in Ders., Human-Built World. How to Think about Technology and Culture, Chicago, London 2005.

24 Michel Callon, Society in the Making: The Study of Technology as a Tool for Sociological Analysis, in: Bujke, Hughes, Pinch (Hg.), The Social Construction of Technological Systems, S. 83-106. Einen guten Überblick über die Fruchtbarkeit des soziologischen Netzwerk-Ansatzes für diverse Wissenschaftsdisziplinen liefern die Bände von Johannes WEYER (Hg.), Soziale Netzwerke. Konzepte und Methoden der sozialwissenschaftlichen Netzwerkforschung, München, Wien 2000 sowie von Bruno LATour, Reassembling the Social: An Introduction to Actor-Network-Theory, New York u. a. 2005.

25 Zur Anwendung dieses Ansatzes bei der Analyse von Standardisierungsprozessen im Bereich der Telekommunikation siehe die anregende Studie von Susanne K. SCHMIDT, Raymund WERLE, Coordinating Technology: Studies in the International Standardization of Telecommunications, Cambridge, London 1998. Einen Versuch, wissenssoziologische Ansätze mit sozialkonstruktivistischen Techniktheorien zu verbinden, liefert Ingo SCHULz-SchäFFER, Akteur-Netzwerk-Theorie. Zur Koevolution von Gesellschaft, Natur und Technik, in: Weyer (Hg.), Soziale Netzwerke, S. $187-210$.

${ }^{26}$ Alain Gras, Grandeur et dépendance. Sociologie des macro-systèmes techniques, Paris 1993. Gras' Interesse geht aber eher in Richtung einer kritischen Beleuchtung der uns »unsichtbar" umgebenden technischen Systeme aus philosophisch-ethischer Perspektive denn in Richtung techniksoziologischer Fragestellungen. 
schreibung, die sich in den zahlreichen Arbeiten spiegelt, die dem sogenannten SCOT-Ansatz (Social Construction of Technology) verpflichtet $\operatorname{sind}^{27}$.

Was, so lautet die Frage, kann an Anregungen aus diesen "neueren « Ansätzen der Technikgeschichtsschreibung zur Vertiefung der Analyse des vorliegenden Falles »europäische Farbfernsehkontroverse« genutzt werden? Vieles. Problematisch ist jedoch, diese Anregungen in eine Systematik zu bringen, die einer grundlegenden Auseinandersetzung mit den einzelnen Theorieströmen gerecht würde. Dennoch wird im folgenden versucht werden - auch auf die Gefahr des Vorwurfes eines Theorie- oder Methodeneklektizismus hin -, einige Inspirationen wiederzugeben, die das Resultat der Beschäftigung mit diesen Ansätzen sind. Diese von Claude Lévy-Strauss inspirierte Arbeitsweise »intellektueller Bastelei « - von ihm als »bricolage« bezeichnet - hat den Vorteil, als Historiker in verwandten Wissenschaftsdisziplinen »wildern« zu können, um Michel de Certeaus bekannte Metapher der kreativen Form von Wissensaneigung durch lesen aufzugreifen ${ }^{28}$.

${ }^{27}$ Zur »Bibel« dieses Ansatzes wurde der bereits zitierte Sammelband von Bijker, Hughes und Pinch »The Social Construction of Techological Systems«. Als Fortsetzung dieser Schule erschien 1994 der von Wiebe Bijker und John Law herausgegebene Sammelband »Shaping Technology/Building Society. Studies in Sociotechnical Change«. Einen Forschungsüberblick über die SCOT-Arbeiten liefert Trevor PINCH, The Social Construction of Technology: A Review, in: Robert Fox (Hg.), Technological Change. Methods and Themes in the History of Technology, Amsterdam 1996, S. 17-36. Eine kritische Auseinandersetzung mit dieser "sozialkonstruktivistischen Wende« im Bereich der Technikgeschichte lieferte Wolfgang König 1993 in einem Aufsatz der Zeitschrift Technikgeschichte. Siehe Wolfgang KöNIG, Technik, Macht und Markt. Eine Kritik der sozialwissenschaftlichen Technikgeneseforschung, in: Technikgeschichte 60 (1993) 3 S. 243-266. Eine amüsant zu lesende Kritik an der »Mode» des sozialen Konstruierens stammt aus der Feder des bekannten amerikanischen Wissenschaftsphilosphen Ian HACKING, Was heiBt soziale Konstruktion? Zur Konjunktur einer Kampfvokabel in den Wissenschaften, Frankfurt a.M. 1999. Neben den SCOT-Arbeiten haben auch innovationstheoretische Ansätze wie die von Bruno Latour oder Karin Knorr-Cetina die technikhistorische Diskussion angeregt. Bruno LATour, When Things Strike Back: A Possible Contribution of >Science Studies ‘ to the Social Sciences, in: British Journal of Sociology 51 (2000) 1 S. 107-123; DERS., Die Hoffnung der Pandora. Untersuchungen zur Wirklichkeit der Wissenschaft, Frankfurt a.M. 2000; Bruno LATOuR, Steve Woolgar, Laboratory Life. The Construction of Scientific Facts, Princeton 1986; Karin Knorr-Cetina, Die Fabrikation von Erkenntnis. Zur Anthropologie der Naturwissenschaft, Frankfurt a.M. 1991. Viele dieser sozialkonstruktivistischen oder kulturanthroplogischen Erkenntnisse wurden bereits Mitte der dreiBiger Jahre diskutiert. Siehe beispielhaft hierzu Ludwik FLECK, Entstehung und Entwicklung einer wissenschaftlichen Tatsache: Einführung in die Lehre vom Denkstil und Denkkollektiv, Basel 1935.

28 Claude LÉvy-STrauss, Das wilde Denken, Frankfurt a. M. 1994, S. 29f. Michel DE CERTEAu, Die Kunst des Handelns, Berlin 1988, S. 307. Eine "Fortführung« dieser Arbeits- und Denkweise findet sich im Konzept der "Hybride« von Bruno Latour, der in seinen Arbeiten immer wieder für die Aufhebung der in seinen Augen »künstlichen« (d.h. vom Menschen ausgedachten und damit wissenschaftshistorisch gewachsenen) Trennung zwischen Natur, Politik und Diskurs plädiert. So fragt er in der Einleitung seines Essays »Nous n'avons jamais été modernes« provozierend: »Est-ce notre faute si les réseaux sont à la fois réels comme la nature, narrés comme le discours, collectifs comme la société «? Siehe Bruno LaTour, Nous n'avons jamais été modernes, 
Konkret sollen diese unterschiedlichen Beobachterperspektiven auf zwei Fragestellungen fokussiert werden: Erstens soll danach gefragt werden, welchen Beitrag der von Thomas Hughes eingeführte Begriff des »technological style « zur Beschreibung der PAL-SECAM-Kontroverse leisten kann. Anders formuliert: War das Scheitern der Standardisierungsbemühungen auch das Resultat unterschiedlicher nationaler Technikstile oder Konstruktionskulturen, die sich im PAL- bzw. SECAM-System manifestierten? Spiegeln sich im Verhalten der zentralen Akteure der Kontroverse unterschiedliche technische, kulturelle oder gar politische Mentalitäten im Sinne der von Pierre Renouvin und Jean-Baptiste Duroselle konstatierten $\gg$ forces profondes ${ }^{29}{ }^{29}$ ?

Zweitens sollen die Verhandlungen im Rahmen der CCIR-Tagungen kommunkationstheoretisch durchleuchtet werden. Können verhandlungstheoretische Modelle, die die Handlungsspielräume der Verhandlungsakteure nach spieltheoretischen und handlungstheoretischen Annahmen analysieren, zum Verständnis der CCIR-Diskussionen in Wien und Oslo beitragen? Handelt es sich bei der PAL-SECAM-Kontroverse letztlich um einen sozial konstruierten Farbenkrach, oder verlief sie nach den Mustern wirtschaftstheoretischer Innovations- und Markteinführungsmodelle?

\subsubsection{PAL und SECAM als Symbole nationaler Technikstile?}

In seinem Aufsatz »The Evolution of Large Technological Systems« schlug Thomas Hughes vor, den in der Kulturgeschichte gebräuchlichen Stilbegriff für die Technikgeschichte nutzbar zu machen:

Historians and sociologists can use style to suggest that system builders, like artists and architects, have creative latitude. Furthermore, the concept of style accords with that of social construction of technology. There is no one best way to paint the Virgin; nor is there one best way to build a dynamo. Inexperienced engineers and laymen err in assuming that there is an ideal dy-

S. 14. Eine kulturhistorische Aneignung des Hybrid-Begriffs findet sich bei Mikael HÅRD, Andrew JAMison, Hubris and Hybris: A Cultural History of Science and Technology, New York, London 2005. Auch Jürgen Schlumbohm verteidigt die in der "microstoria " anzutreffende Arbeitsweise der mbricolage «. Zwar werde der Mikrogeschichte, wenn diese den Versuch unternehme (z. B. bei Carlo Ginzburg), Mikro- und Makroperspektiven miteinander zu verbinden, nicht selten der Vorwurf eines »Eklektizismus hinsichtlich theoretischer Ansätze « gemacht, aber die besondere Neigung zur »bricolage« verlange dies eben! Da es bislang keine "Theorie der Aggregation« gebe, müsse man mit dieser Kritik nun einmal leben. Jürgen ScHLuMBOHM, Mikrogeschichte - Makrogeschichte: Zur Eröffnung einer Debatte, in: DERS. (Hg.), Mikrogeschichte Makrogeschichte. Komplementär oder inkommensurabel?, Göttingen 1998, S. 28 f.

29 Pierre Renouvin, Jean-Baptiste Duroselle, Introduction à l'histoire des relations internationales, Paris 1991. Einen guten Überblick über die Geschichte der französischen Geschichtsschreibung der internationalen Beziehungen liefert Georges Henri -Soutou, Die französische Schule der Geschichte internationaler Beziehungen, in: LoTH, Osterhammel (Hg.), Internationale Geschichte, S. 31-42. 
namo toward which the design community whiggishly gropes. Technology should be appropriate for time and place, this does not necessarily mean that it be small and beautiful ${ }^{30}$.

Bereits 1979 hatte Hughes die Nützlichkeit des Stilbegriffs bei der Beschreibung technologischer Entwicklungen in regional begrenzten Räumen demonstriert und damit dem Konzept regionaler Industrialisierung technikhistorische "Rückendeckung “ gegeben ${ }^{31}$. In der Bundesrepublik wurde das Konzept regionaler und nationaler Technikstile unter anderem von Joachim Radkau, Ulrich Wengenroth, Wolfgang König sowie Mikael Hård und Andreas Knie aufgenommen und kritisch auf seine Brauchbarkeit hinterfragt. Während Radkau den Stilbegriff dazu nutzte, die Frage nach dem »deutschen Weg « im IndustrialisierungsprozeB zu stellen und zu dem Resultat kam, daß ein nationaler technologischer Stil nicht an bestimmten Techniken festzumachen sei, sondern eher auf »anthropologischen Grundlagen«, d.h. der Art und Weise der Organisation von Produktionsprozessen und des Umgangs mit technischen Artefakten basiere ${ }^{32}$, wies Ulrich Wengenroth in seiner vergleichenden Studie über die Unternehmensstrategien britischer und deutscher Stahlunternehmer nach, daß der »Siegeszug « der deutschen Stahlprodukte weniger mit technischen Innovationen und deutscher Wertarbeit als mit erfolgreicher Kartell- und Schutzzollpolitik zu tun hatte ${ }^{33}$. In seiner vergleichenden Studie des amerikanischen, britischen, deutschen und französischen Maschinenbaus zwischen 1850 und 1930 schlug Wolfgang König vor, den von Hughes eingeführten Stilbegriff durch den der »Technik- und Konstruktionskulturen « zu ersetzen, da der Stilbegriff Reste eines Technikdeterminismus beinhalte und die semantischen Konnotationen des Stilbegriffs mit der Kunst- und Literaturwissenschaft den instrumentellen Charakter der Technik in den Hintergrund dränge ${ }^{34}$. Mikael Hård und Andreas Knie haben in ihrer

30 Thomas P. Hughes, The Evolution of Large Technological Systems, in: BukER, Hughes, Pinch (Hg.), The Social Construction of Technological Systems, S. 68.

31 Thomas P. Hughes, Regional Technological Style, in: Sigvard Strand (Hg.), Technology and its Impact on Society, Stockholm 1979, S. 212 f.

32 Joachim RadKaU, Technik in Deutschland. Vom 18. Jahrhundert bis zur Gegenwart, Frankfurt a.M. 1989.

${ }^{33}$ Ulrich WENGENROTH, Unternehmensstrategien und technischer Fortschritt. Die deutsche und britische Stahlindustrie 1865-1895, Göttingen 1986. Obwohl der Stilbegriff bei Wengenroth ein gewisses »Unbehagen« erzeugte, sieht er in der neueren Debatte um die Aneignung (appropriation) von Technologien und deren Konsum eine neue »Chance« für den Begriff. »Das Unbehagen galt dem >Stilk-Begriff und war weniger Ausdruck der Skepsis, ob es überhaupt signifikante kulturelle Unterschiede in der Technik gebe«. Ulrich WenGENROTH, Gute Gründe. Technisierung und Konsumentscheidungen, in: Technikgeschichte 71 (2004) 1 S. 15.

34 „Er klammert das Phänomen aus, daß unterschiedliche soziokulturelle Bedingungen auch zu ganz verschiedenen technischen Lösungen führen können, welche wenig miteinander gemein haben«. Wolfgang KöNIG, Künstler und Strichezieher. Konstruktions- und Technikkulturen im deutschen, britischen, amerikanischen und französischen Maschinenbau zwischen 1850 und 1930, Frankfurt a.M. 1999, S. 219 f. Ähnlich, aber aus wirtschaftshistorischer Sicht argumentie- 
vergleichenden Studie zur Entwicklung des Diesel-Motors in Deutschland und Frankreich den Stil-Begriff zum Anlaß genommen, Überlegungen zu einer "Grammatologie« der Technik anzustellen, die in Anlehnung an die Arbeiten Pierre Bourdieus sozial geprägte Diskursregeln als entscheidende Ursache für die Entstehung disziplinärer Kanons und technischer Stile ausmacht ${ }^{35}$.

Diese wenigen Beispiele zeigen, daß der Begriff des »Stils« in der Technikgeschichte sehr unterschiedlich definiert oder interpretiert wird. Mit ihm können demnach sowohl nationale Eigenheiten in der Art und Weise der Organisation, Produktion und Vermarktung technischer Artefakte als auch unternehmens- oder industriepolitische Strategien gemeint sein. Im Gegensatz zu Wolfgang König könnte man jedoch argumentieren, daß gerade diese Unbestimmtheit oder Offenheit des Begriffs Technikstil dazu geeignet scheint, die kulturgeschichtliche Dimension technischer Artefakte und Prozesse zu beschreiben. Für die nur schwierig zu erfassende und begrifflich spezifizierbare Beziehung zwischen Technik, Politik und Identität kann der Begriff des Technikstils, so die Auffassung des Autors, wichtige Anregungen leisten ${ }^{36}$. Besonders fruchtbar scheint eine Auseinandersetzung mit dem Stilbegriff dort, wo - im Sinne Pierre Bourdieus - das symbolische Kapital von Technik (SECAM als »champion national«) von größerer Wirkmächtigkeit zu sein scheint als die funktionale oder wirtschaftliche Bedeutung materieller technischer Artefakte oder technologischer Systeme. Die Renaissance des Stilbegriffs in der Wissenschaftsgeschichte im Rahmen der Auseinandersetzung mit dem lange vernachlässigten Werk von Ludwik Fleck zeigt, wie fruchtbar eine entsprechende Problematisierung des Stilbegriffs für eine Kulturgeschichte der Technik sein könnte ${ }^{37}$.

rend Fred MANske, Facharbeiter und Ingenieure im »deutschen Produktionsmodell «: Nationale Technikstile und die internationale Konkurrenzfähigkeit reifer Industrieländer, in: WSI-Mitteilungen. Zeitschrift des Wirtschafts- und Sozialwissenschaftlichen Instituts des Deutschen Gewerkschaftsbundes 47 (1994) 7 S. 415-424.

35 Mikael HARD, Andreas KNIE, The Grammar of Technology. German and French Diesel Engineering 1920-1940, in: Technology \& Culture 40 (1999) 1 S. $26-46$.

36 Siehe hierzu auch die kritische Auseinandersetzung mit dem Begriff Technikstil in dem Band von Klaus Plitzner (Hg.), Technik. Politik. Identität. Funktionalisierung von Technik für die Ausbildung regionaler, sozialer und nationaler Selbstbilder in Österreich, Stuttgart 1995.

37 FLECK, Entstehung und Entwicklung einer wissenschaftlichen Tatsache. Zu Fleck siehe Rainer EgLOFF (Hg.), Tatsache - Denkstil - Kontroverse: Auseinandersetzungen mit Ludwik Fleck, Zürich 2005. Ende der zwanziger, Anfang der dreiBiger Jahre des 20. Jahrhunderts wird der aus der Kunstgeschichte übernommene Stilbegriff sowohl von Soziologen (Karl Mannheim und Alfred Schütz) als auch von Historikern (Johan Huizinga) in kreativer Weise zur Entwicklung kulturtheoretischer oder kulturhistorischer Analysen der Wissenschaft (Mannheim), Gesellschaft (Schütz) oder Geschichte (Huizinga) genutzt. Siehe hierzu die gelungene Darstellung von Peter BURKE, Was ist Kulturgeschichte?, Frankfurt a.M. 2005. Schon Max Weber benutzte den Begriff des Stils, um unterschiedliche Unternehmertypen zu beschreiben. Max WEBER, Die protestanti- 
Ein Faktor, der bei dem Vergleich deutscher und französischer Technik meist auftaucht, ist der der unterschiedlichen Ausbildungssysteme im Ingenieurswesen ${ }^{38}$. Auch König weist auf die Besonderheiten der französischen Elite-Ausbildung hin, die sich - und dies ist wohl die eigentliche Besonderheit - in der Berufswahl bzw. den späteren Karrieren der Ingenieure wiederspiegeln. Für viele Abgänger der École Polytechnique, die nach ihrem Abschluß zur Vorbereitung auf den Staatsdienst auf eine der »Écoles d'Application« wie die Écoles des Mines oder die Écoles des Ponts et Chaussées gingen, stand der spätere Berufsweg schon mit der Wahl ihres Ausbildungswegs fest. Ähnliche Curricula warteten auch auf die Abgänger der École Centrale des Arts et Manufactures, die sogenannten »Centraliens«, sowie auf die »Gadzarts«, die Absolventen der École des Arts et Métiers. Alle diese Elite-Ausbildungsstätten zeichnen sich durch einen »Corpsgeist« aus, der unter anderem zu sehr festen Rekrutierungsgewohnheiten in der Privatindustrie führen kann, die Pierre Bourdieu treffend als "Strategien der Reproduktion « einmal erreichter realer und symbolischer Machtpositionen beschrieben hat $^{39}$.

Die teilweise sehr strikten Ausgrenzungen, welche dieses System elitärer Technikerausbildung in Frankreich für Nicht-Absolventen bedeuten konnte (und heute noch bedeuten kann), bekam auch SECAM-Entwickler Henri de France zu spüren. Genoß Henri de France in der französischen Öffentlichkeit das Bild des genialen Erfinders, eindrucksvoll demonstriert in den zahlreichen hohen Auszeichnungen (so wurde er u. a. 1965 von de Gaulle zum Offizier der "Légion d'honneur« ernannt), begegneten ihm die in den französischen Eliteinstituten ausgebildeten Ingenieure der ORTF (die meisten waren

sche Ethik und der Geist des Kapitalismus, in: Johannes Winckelmann (Hg.), Die protestantische Ethik I. Eine Aufsatzsammlung, Hamburg ${ }^{3}$ 1973, S. 58. Eine wissenschaftsphilosophische Auseinandersetzung mit dem Stil-Begriff findet sich bei Ian HACKrng, "Style« for Historians and Philosophers, in: Studies in History and Philosophy of Science 23 (1992) S. 1-20.

38 Nicholas Ziegler, Governing Ideas: Strategies for Innovation in France and Germany, Ithaca 1997. Zum elitären Ausbildungssystem von Ingenieuren an französischen »Grandes Écoles« siehe Vincent Troger, L'histoire de l'enseignement technique: entre les entreprises et l'État, la recherche d'une identité, in: Annales. Histoire, économie et société (1989) S. 593-610. Zu dem sehr ähnlichen, aber seltener diskutierten System in Belgien siehe Dominique GrootaERs, Histoire de l'enseignement technique et professionnel en Belgique 1860-1960, Bruxelles 1994.

${ }^{39}$ Als Fallstudie aus dem technischen Bereich siehe den Aufsatz von Charles DAY, The Careers of Graduates of the Écoles des Arts et Métiers in the French Automobile Industry, 1880-1940, in: Canadien Journal of History 24 (1994) S. 305-331. Besonders bekannt ist das Beispiel der Spannungen zwischen den Ingenieuren der École des Ponts et Chaussées und denen der École des Mines, die, obwohl beide »Polytechniciens «, in den fünfziger und sechziger Jahren über die in Frankreich einzuschlagende Richtung in der Reaktorentwicklung stritten. Siehe HEcHT, The Radiance of France. Eine grundlegende soziologische Untersuchung der strukturellen Dimension dieses Systems elitärer Ausbildung und Reproduktion von Macht hat Pierre Bourdieu 1989 mit seinem Werk »La noblesse d’État. Grandes Écoles et esprit de corps« vorgelegt. 
Abgänger der École Polytechnique) mit deutlicher Reserviertheit ${ }^{40}$. Wie der technische Direktor der ORTF, Claude Mercier, 1966 formulierte, war das ORTF-Corps das Spezialistenteam in Sachen Fernsehtechnik in Frankreich, dessen Kompetenz auch außerhalb Frankreichs zur Entwicklung der Fernsehtechnik beitragen sollte:

Le corps des ingénieurs de l'ORTF est l'organe specialisé en France dans l'engineering de Radiodiffusion et Télévision. $\mathrm{ll}$ intervient de differentes manières: il oriente l'industrie en établissant les spécifications des matériels et des installations, il exige d'elle des performances qui font la renommée internationale des materiels français, il conçoit non seulement les spécifications des matériels mais leur meilleure articulation entre eux pour une meilleure circulation des modulations entre leurs multiples sources et les émetteurs, il conseille les producteurs de programmes pour qu'ils puissent tirer le meilleur des possibilités des matériels. La contribution des Services Techniques ORTF a été et demeure considerable dans le développement des services de télévision non seulement en France mais plus genéralement en Europe, en coopération avec les services analogues des grands organismes étrangers de radiodiffusion et de télévision ${ }^{41}$.

Trotz dieses Selbstbewußtseins konnten die ORTF-Ingenieure im Falle der Farbfernsehfrage ihre eigene Position nicht gegenüber den politischen Interessen durchsetzen. Obwohl die führenden Ingenieure der ORTF alles daran gesetzt hatten, in Oslo der sowjetischen NIR-Variante zum Durchbruch zu verhelfen, hatten sie auf den Entscheidungsprozeß keinerlei Einfluß. Wie aus den Interviews mit zentralen technischen Akteuren der SECAM-Entwicklung in Frankreich hervorgeht, basierte dieser Einsatz für das NIR-System neben dem Wunsch, zu einem einheitlichen europäischen Standard in Europa zu gelangen, auch auf einer gewissen Sympathie für die »Einfachheit« des PALSystems im Vergleich zu der technisch anspruchsvolleren SECAM-Lösung. Als Walter Bruch im August 1966 vom Telefunken-Vorstandvorsitzenden Dr. Herriger aufgefordert wurde, auf einigen Seiten einen knappen technischen Vergleich der drei Systeme NTSC, PAL und SECAM zu formulieren, gab Bruch zu bedenken:

Ich muB Ihnen dazu mitteilen, daB ein solcher Vergleich leider nicht so einfach ist, denn abgesehen von NTSC unterscheiden sich die beiden Systeme PAL und SECAM in ihren prinzipiellen

40 Zwischen 1960 und 1968 konnten Studierende an der École polytechnique sogar einen speziellen Ausbildungszweig wählen, der auf die Anforderungen als ORTF-Ingenieur vorbereitete. Wie Jérôme Bourdon und Catherine Grünblatt gezeigt haben, führte die wachsende Bedeutung des Fernsehens ab Beginn der fünften Republik zu einer Emanzipation der Fernsehingenieure im „Corps interministériel des ingénieurs des télécommunications et de la radiodiffusion «, also der staatlich ausgebildeten und geprüften Ingenieure für den Dienst in Institutionen unter der Leitung des Post- und Telekommunikationsministeriums. Jérôme Bourdon, Catherine GründlatT, Les ingénieurs de la télévision dans les années soixante, in: Bulletin du Comité d'histoire de la télévision 17 (décembre 1987, janvier 1988) S. 3-38. Siehe auch Pascale FAUCHART, Dominique FrICHOT, Les techniciens de la télévision, in: Bulletin du Comité d'histoire de la télévision 19 (1989) S. 5-26 und 20 (1989) S. 3-14.

41 So Claude Mercier, zitiert nach Bourdon, GrüNBLATt, Les ingénieurs de la télévision dans les annees soixante, S. 6f. 
Eigenschaften nur wenig. Der Unterschied zwischen PAL und SECAM kommt fast ausschließlich dadurch zustande, daB die Modulationseinrichtungen bei SECAM so kompliziert sind, daB es außer der CSF noch niemand gelungen ist, einen brauchbaren SECAM-Modulator herzustellen. PAL dagegen ist so einfach, daß heute alle wichtigen Laboratorien sich eigene PAL-Modulatoren hergestelit haben. Die Unvollkommenheit der SECAM-Modulatoren und Demodulatoren hat zu den oft sehr extremen Unterschieden zwischen PAL und SECAM bei Demonstrationen geführt ${ }^{42}$.

Wie in Kapitel 2. geschildert wurde, kann der Vorwurf Bruchs an die Adresse von de France, das SECAM-System sei »erbastelt« und »nicht logisch« entwickelt, problemlos auch auf Bruchs Arbeitsweise übertragen werden. Wie Franz-Josef In der Smitten, ehemaliger Leiter des WDR-Farbfernsehversuchsstudios im Interview mitteilte, brachte es Bruch zu einer besonderen "Meisterschaft" in der Erfindung von Störsignalen, welche die relativen Schwächen des SECAM-Systems bei Systemvergleichen hervorhoben ${ }^{43}$ ! Diese Aussagen legen jedoch nahe, daß man - wie Joachim Radkau betont - einen Technikstil wohl kaum an einer einzelnen Technologie festmachen $k^{k a n n}{ }^{44}$. FaBt man in der Beschreibung der beiden Systementwicklungen jedoch die technischen, institutionellen, wirtschaftlichen, politischen und nicht zuletzt personenbezogenen Faktoren zusammen, lassen sich durchaus unterschiedliche Art und Weisen des »Umgangs « mit beiden Systemen feststellen, die man als unterschiedliche Denk- und Technikstile beschreiben kann. Während man in Frankreich beim Prozeß der Erfindung, Entwicklung und Durchsetzung des SECAM-Systems wegen der engen Verzahnung technischer, wirtschaftlicher und politischer Entscheidungsträger von einem nationalistisch geprägten Technikstil sprechen könnte, dominierten bei der Durchsetzung des PAL-Systems in Deutschland marktwirtschaftliche Intentionen.

Allerdings ist es wichtig, die in Frankreich wie in der Bundesrepublik zur Durchsetzung der jeweiligen Systemalternativen geführten nationalen Diskurse von denjenigen auf internationalem Parkett zu unterscheiden. Bestand die

42 Brief von Walter Bruch an Felix Herriger, Hannover, 11.08. 1966, in: AEG-Telefunken- Archiv, Deutsches Technikmuseum Berlin, Signatur GS 1647.

43 Im Interview, das Franz-Josef In der Smitten mit Heide Riedel geführt hat, heißt es diesbezüglich: "Zu SECAM: Ich habe die Glanzleistungen der französischen Ingenieure bewundert, denen es immer wieder gelungen ist, das SECAM-System weiter $\mathrm{zu}$ verbessern, wieder einen Schritt zu modifizieren. Worauf Herr Bruch damals regelmäBig sehr schnell reagierte. Er hat sich sofort bestimmte Signale ausgedacht, um den Franzosen zu zeigen, seht ihr, das kann SECAM nicht «. In: RIEDEL, Bruch, PAL -Das Farbfernsehen, S. 151. Diese Äußerungen bestätigten sowohl Franz-Josef In der Smitten als auch Michael Hausdörfer im Interview mit dem Autor. 44 Treffender als der Begriff des Technikstils könnte in diesem Fall die von Thomas P. Hughes eingebrachte Metapher des "reverse salient« sein, mit der Hughes unerwartete Folgeprobleme einer anfangs durchaus erfolgreichen Entwicklung eines technischen Systems beschreibt. Im Sinne dieser Theorie könnte man die Probleme der Farbtonstabilität des NTSC-Systems, die letztlich zu den europäischen Weiterentwicklungen PAL und SECAM führten, als »reverse salient point « des NTSC-Systems beschreiben. 
französische Strategie hier in einer offenen und aggressiven Politisierung des Farbfernsehthemas, ist auf bundesdeutscher Seite eine gezielte Entpolitisierungsstrategie erkennbar. Wie die Beschreibung der CCIR-Verhandlungen in Wien und Oslo gezeigt hat, handelte sich die deutsche Delegation mit dieser Entscheidung, den technischen Diskurs strikt vom politischen Entscheidungsprozeß zu trennen, die Sympathien vieler Länder ein. Zahlreiche Delegationen, die gegen eine ernsthafte Diskussion des SECAM-Systems als technische Alternative für ein europäisches System durchaus nichts einzuwenden hatten, wollten sich aber gegen die Politisierung des Entscheidungsfindungsprozesses zur Wehr setzten. Als Werner Nestel seinen Vorstandskollegen von Telefunken über die Wiener Tagung berichtete, zeigte er sich besonders erfreut darüber, daß die Politisierung der Farbfernsehfrage durch die Franzosen diesen im allgemeinen mehr geschadet als genutzt habe ${ }^{45}$.

Das bewußt auf technische Argumentation reduzierte Auftreten der Bundesregierung wurde, wie der Telefunken-Vertreter Dr. Siewert in Bonn in einem Brief an Werner Nestel vom 3. November 1966 mitteilte, zur besten Werbung für PAL im Ausland:

Die Tatsache, daß die Bundesregierung zwar nach wie vor auf politische Argumente verzichtet, aber umso tatkräftiger im Ausland darauf hinweist, daß PAL als das technisch leistungsfähigste System den Sieg errungen hat, ist an sich schon ein Politikum. Vor allem, wenn die Bundesregierung erklärt, daß sie es nicht verstehen könnte, wenn sich andere Länder nicht nach technischen und wirtschaftlichen Gesichtspunkten entscheiden würden. Keinenfalls aber beabsichtigt die Bundesregienung, , in Konkurrenz mit den französischen Pressionen zu treten ${ }^{46}$.

Mit ihrer Entpolitisierungsstrategie machte sich die Bundesregierung so unbewußt zum idealen Werbeträger für das PAL-System. Ähnlich definierte auch Walter Bruch seine Rolle im Farbfernsehstreit als »Botschafter der deutschen Technik«. Gefragt nach dem Erfolg seiner PAL-Mission in China antwortete Bruch in einem Interview mit Funkschau-Chefredakteur Karl Tetzner: "Ich betrachte mich, und das haben schon andere vor mir gesagt, abgesehen von meiner kleinen Entwicklung, als ein Botschafter der deutschen Technik - und das war letztlich doch die Tendenz meines Besuches. Ich habe mich dort nicht hingestellt und für meine Firma Propaganda gemacht - ich habe für die deutsche Technik Propaganda gemacht « ${ }^{47}$.

Ein wenig überspitzt könnte man demnach formulieren, daß sich der französische Technikstil im Sinne der »champions nationaux« durch die nationa-

45 Siehe das Protokoll der Telefunken-Vorstandssitzung vom 22.4.1965 in Berlin/Punkt 24: Bericht Prof. Nestel über Wiener Konferenz, in: AEG-Telefunken-Archiv, Deutsches Technikmuseum Berlin, Signatur VS GS 038.

46 Brief von Dr. Siewert an Werner Nestel bezüglich des Besuchs von Nestel bei Dr. Frank vom Auswärtigen Amt, Bonn, 3.11.1966, in: AEG-Telefunken-Archiv, Deutsches Technikmuseum Berlin, Signatur GS 1647.

${ }^{47}$ Transkription des Interviews von Prof. Tetzner mit Walter Bruch am 9.2. 1973 in Icking, in: Privatarchiv Karl Tetzner, Icking. 
listisch aufgeladene Politisierung des SECAM-Systems auszeichnete, während man in der Bundesrepublik auf politischer wie privatwirtschaftlicher Seite erfolgreich den Mythos der besseren Technik »Made in Germany « verkaufte. Ist diese Gegenüberstellung »politique de la grandeur« versus »Made in Germany « in ihrer Zuspitzung gewagt, bringt sie dennoch die symbolische Dimension der Farbfernsehkontroverse im Sinne einer politischen Kulturgeschichte der Technik auf den Punkt.

\subsubsection{Farbfernsehverhandlungen: Theorie und Praxis}

Bereits mehrfach wurde auf die Bedeutung unterschiedlicher Strategien hingewiesen, welche sich die an der Farbfernsehdiskussion beteiligten Akteure zur Durchsetzung ihrer Verhandlungsposition in Wien und Oslo zurechtgelegt hatten. Sowohl Soziologen als auch Politologen und Wirtschaftswissenschaftler haben sich in den letzten Jahren intensiv mit der Analyse von Standardisierungsprozessen beschäftigt. Die Soziologen haben dies zumeist anhand handlungstheoretischer Modelle wie beispielsweise des »actor-network «-Ansatzes von Michel Callon oder des »akteurzentrierten Institutionalismus« (Renate Mayntz, Raymund Werle) getan, die beide auf der sogenannten »rational-choice«-Theorie basieren ${ }^{48}$. Auf Webers Begriff »zweckrationalen Handelns« aufbauend wurde der »rational choice«-Ansatz vor allem von dem amerikanischen Soziologen Talcott Parsons zu einer Theorie rationalen Handelns ausgeweitet, die - in utilitaristischer Perspektive - postuliert, daß Entscheidungsträger versuchen, ihr komplexes Umfeld durch eine Zweck-Mittel-Orientierung zu strukturieren und zu steuern.

Auch in der Politikwissenschaft findet der »rational choice «-Ansatz breite Verwendung, so beispielsweise zur Analyse mikropolitischer Entscheidungsprozesse oder internationaler Beziehungen ${ }^{49}$. Politikwissenschaftliche und soziologische Fragestellungen verbinden sich zudem in organisations- und institutionentheoretischen Ansätzen, die sich durch mehrdimensionale Analy-

48 Siehe beispielsweise Johannes WEYER, Akteurstrategien und strukturelle Eigendynamiken. Raumfahrt in Westdeutschland 1945-1965, Göttingen 1993; Raymund WERLE, Rational Choice und rationale Technikentwicklung - Einige Dilemmata der Technikkoordination, in: Jahrbuch Technik und Gesellschaft, Frankfurt a.M. 1995, S. 49-76; DERS., Politische Techniksteuerung durch europäische Standardisierung?, in: Herbert Kubicek, Peter SEeger (Hg.), Perspektive Techniksteuerung. Interdisziplinäre Sichtweisen eines Schlüsselproblems entwickelter Industriegesellschaften, Berlin 1993, S. 129-142. Johannes WEYER, Ulrich KIRCHNER, Lars RIEDL, Johannes ScHMidT, Technik, die Gesellschaft schafft. Soziale Netzwerke als Ort der Technikgenese, Berlin 1997; Volker SchneIDER, Technikentwicklung zwischen Politik und Markt: Der Fall Bildschirmtext, Frankfurt a. M., New York 1989.

49 Willi KüPPER, Günter OrTMANN (Hg.), Mikropolitik. Rationalität, Macht und Spiele in Organisationen, Opladen 1992; Dietmar Braun, Theorien rationalen Handelns in der Politikwissenschaft. Eine kritische Einführung, Opladen 1999; Jürgen HarTmanN, Internationale Beziehungen, Opladen 2001. 
seperspektiven auszeichnen und versuchen, subjektbezogene und strukturelle Handlungsrahmen politischer Akteure miteinander zu verbinden ${ }^{50}$.

In wirtschaftstheoretischen Arbeiten tauchen handlungstheoretische Ansätze unter anderem in jenen Arbeiten auf, die sich mit dem Phänomen der Standardisierung beschäftigen ${ }^{51}$. Besondere publizistische Aufmerksamkeit hat beispielsweise das Scheitern der Einigung auf einen weltweiten HDTVStandard gefunden ${ }^{52}$. Zwar gibt es seit einigen Jahren Bemühungen, die in den verschiedenen Wissenschaftsdisziplinen meist separat voneinander geführten Diskussionen über die Bedeutung und Rolle von Standards im gesellschaftlichen, wirtschaftlichen und politischen Leben einander anzunähern, doch zeugt die Publikationslandschaft meist von geschlossenen Fachdiskursen. Von einer fruchtbringenden interdisziplinären Diskussion ist man weit entfernt ${ }^{53}$.

Was können die soeben erwähnten Theorien und Ansätze zur Analyse der PAL-SECAM-Kontroverse beitragen? Leider hat sich das Ergebnis der Beschäftigung mit wirtschaftstheoretischen und soziologischen Netzwerk- und

50 Siehe beispielsweise Gerhard GöHLER (Hg.), Die Eigenart der Institutionen. Zum Profil politischer Institutionentheorie, Baden-Baden 1994; Patrick FrIDENSON, Les organisations, un nouvel objet, in: Annales. Économie, Sociétés, Civilisations 44 (1989) 6 S. 1461-1477; Karl-Siegbert REHBERG, Institutionenwandel und die Funktionsveränderung des Symbolischen, in: Leviathan Sonderheft 16 (1996) S. 94-118; Uwe SCHimank, Organisationssoziologie, in: Harald KerBer, Arnold Schmieder (Hg.), Spezielle Soziologien. Problemfelder, Forschungsbereiche, Anwendungsorientierungen, Reinbek bei Hamburg 1994, S. 240-254.

51 Für den Bereich der Informationstechnik siehe Brian KaHIN, Janet AbBate (Hg.), Standards Policy for Information Infrastructure, Cambridge, London 1995. Stanley BeSEN, Joseph FARRELL, Choosing How to Compete: Strategies and Tactics in Standardization, in: Economic Perspectives 8 (1994) S. 117-131.

52 Jürgen BischoFf, Die politische Ökonomie von HDTV, Frankfurt a.M. 1993; Corey P. CARbonara, HDTV: An Historical Perspective, in: Lou Casabianca (Hg.), The New TV. A Comprehensive Survey of High Definition Television, Westport 1992, S. 3-26; Renate DöRR, Die HDTV-Entscheidung. Eine Fallstudie zum EntscheidungsprozeB in der EG, Tübingen 1994; HzusER, Hochauflösendes Fernsehen; Hans-Joachim KLEINSTEUBER, HDTV-Politik, in: Rundfunk und Fernsehen (1994) S. 5-23. Eine interessante politologische Analyse des Scheiterns der HDTV-Standardisierungsbemühungen, die von der Fragestellung viele Ähnlichkeiten mit der Analyse der PAL-SECAM-Kontroverse aufweist, liefert die französische Politologin Florence BraY, La télévision haute définition. Naissance et mort d'un grand projet européen, Paris 2001.

53 Lobend zu erwähnen ist in diesem Zusammenhang die von Prof. Wilfried Hesser am Institut für Standardisierung und Technisches Zeichnen der Universität der Bundeswehr in Hamburg entfaltete Aktivität, Forscher aus den unterschiedlichsten Fachrichtungen im Rahmen des seit 1997 regelmäßig veranstalteten »Interdisciplinary Workshop on Standardization « zusammenzubringen. Die aus den Symposien hervorgehenden Publikationen spiegeln die fachliche Breite und inhaltliche Vielfalt, die das Thema Standardisierung aus interdisziplinärer Perspektive bietet. Im Rahmen des zweiten interdisziplinären Workshops wurde auch vom Autor ein technikhistorischer Beitrag geleistet. Andreas FICKers, Standardization as an Object of Systemic Technical Historiography - The Case of Colour Television, in: Wilfried Hesser (Hg.), Proceedings of the Second Interdisciplinary Workshop on Standardization, Hamburg 1999, S. 118-141. 
Akteurtheorien insgesamt als weniger ergiebig herausgestellt als erhofft. Vor allem die auf der formal-beschreibenden Ebene verharrenden Theorien der Standardisierung aus wirtschaftstheoretischer Perspektive, wie sie beispielsweise von Pelkmans und Beuter ${ }^{54}$ sowie Heuser ${ }^{55}$ in ihren Studien zum Einsatz kommen, scheinen wenig geeignet, die komplexe shistorische Wirklichkeit« des europäischen Standardisierungsversuchs im Bereich des Farbfernsehens erklären zu können. Zwar werden in beiden Studien die unterschiedlichen Kompatibilitätskriterien fernsehtechnischer Standards ${ }^{56}$ sowie die am Standardisierungsprozeß beteiligten Akteure ${ }^{57}$ herausgearbeitet, doch reduzieren sich die Handlungs- und Verhaltensoptionen der einzelnen Akteure auf formale Muster, die mit Hilfe spieltheoretischer Modelle simuliert werden.

Die Verbindung des Instrumentariums der Spieltheorie mit den Prämissen von zweckrational handelnden Akteuren, die ihren Nutzen zu optimieren versuchen, führt im Ergebnis zu einer sozialwissenschaftlichen Theorie interdependenten Handelns, welche aus Menschen "Spieler « mit einer begrenzten Anzahl von Spielzügen und taktischen Manövern machen, die bei der strategischen Wahl ihrer möglichen Verhaltensweisen eng definierten Interessen folgen. Sicherlich hat die Spieltheorie wie jede andere Theorie die Funktion, vereinfachende Formalisierungen der $\mathrm{zu}$ analysierenden Vorgänge zu ermöglichen, damit, wie Michael Zürn formuliert, »Einsichten gewonnen werden können, die ansonsten im Dickicht der Komplexität verborgen bleiben « ${ }^{58}$. Allerdings hat man bei vielen spieltheoretischen Darstellungen von Standardisierungsprozessen den Eindruck, da $\beta$ sie - in Luhmann-Jargon formuliert »die Komplexität so weit reduzieren«, daß der Handlungsspielraum ihrer Ak-

54 Jacques Pelkmans, Rita Beuter, Standardization and Competitiveness: Private and Public Strategies in the EC Colour TV Industry, Paper for the INSEAD Symposium "Product Standardization as a Tool of Competitive Strategy«, 9.-10. Juni 1986, Maastricht 1986.

55 HeusEr, Hochauflösendes Fernsehen.

56 Pelkmans und Beuter unterscheiden drei Kompatibilitätskriterien, die im Falle einer erfolgreichen Standardisierung realisiert werden müssen: 1. »intra-network compatibility« (Studiotechnik), 2. »inter-network compatibility« (Sendetechnik) und 3. »compatibility with existing television systems« (Empfängertechnik).

57 Nach Heuser sind mindestens fünf Gruppen von Akteuren an der Aushandlung von Fernsehstandards beteiligt: 1. Geräteindustrie, 2. Sendeanstalten, 3. Standardisierungsorganisationen; 4. Politik bzw. staatliche Stellen (z. B. Post) und 5. Patentträger.

58 Im Lexikon der politischen Begriffe definiert Michael Züm die Spieltheorie wie folgt: »Spieltheorie ist eine mathematische Theorie, in der aus einer Reihe von Axiomen mit Hilfe von logisch einwandfreien Deduktionen bestimmte Aussagen gefolgert werden. Die Spieltheorie leistet eine formalisierte Darstellung von interdependenten Entscheidungsstrukturen. Sie ist mithin zunächst keine substantielle sozialwissenschaftliche Theorie, sondern ein Instrument der Theoriebildung«. Michael ZürN, Spieltheorie, in: ZüRN, Michael, Spieltheorie, in: Dieter NoHLEN (Hg.), Lexikon der Politik, Bd. 6, Internationale Beziehungen, München 1993, S. 502-510. 
teure im übertragenen Sinne auf den eines Schalters mit drei bis maximal vier Funktionen beschränkt wird.

Zwar lassen sich mit Hilfe komplexerer spieltheoretischer Modelle auch komplizierte Verhandlungssituationen simulieren, doch hinterlassen die Resultate dieser simulierten Szenarien - zumindest in der Wahrnehmung des Autors - eine Theoriewelt, die mit der psychischen und sozialen Komplexität der lebensweltlichen Realität handelnder Menschen nur wenig gemein hat ${ }^{59}$. Ist es doch gerade die in der Dichte eines einzelnen historischen Ereignisses zum Vorschein kommende Komplexität ineinandergreifender Strukturen, mehrschichtiger Kontexte und konkurrierender Handlungsentwürfe einzelner Akteure, die den Historiker beim näheren Hinsehen zum Zeugen der prinzipiellen Offenheit aller historischer Verläufe macht. Diese Einsicht zwingt zur Abkehr von der Deutung des Menschen als »homo oeconomicus« und verlangt eine Theorie sozialen Handelns, die über rein zweckrationale Handlungsmotivationen oder -spielräume hinausgeht ${ }^{60}$. Bereits der $» E$ Erfinder« des Begriffs »zweckrationalen Handelns«, Max Weber, sah diesen lediglich als

59 In der Spieltheorie werden kooperative und nichtkooperative Spiele unterschieden. Bei kooperativen Spielen sind verbindliche Absprachen möglich, die von einer übergeordneten Sanktionsgewalt durchgesetzt werden können. Bei nichtkooperativen Spielen wird davon ausgegangen, daß selbst die Kommunikation zwischen den Spielern keine verbindlichen Absprachen erzeugt. Bei nichtkooperativen Spielen unterscheidet man wiederum Nullsummenspiele und Variablesummenspiele. Erstere haben als zentrales Merkmal, einen totalen Konflikt abzubilden, bei dem der Gewinn der einen Seite automatisch einen Verlust der anderen Seite bedeutet. In Variablesummenspielen gibt es von einem kollektiven Standpunkt aus betrachtet bessere und schlechtere Interaktionsergebnisse. Es gibt drei Lösungskonzepte für nichtkooperative Spielsituationen: 1. Die Maximin-Lösung: Sie zeigt das Interaktionsergebnis an, welches zustande kommt, wenn die beteiligten Parteien gemäß der Regel »Maximiere dein Minimum« handeln, d.h. man wählt das Verhalten, das im schlechtesten Fall noch das beste Ergebnis erzielt. 2. Das Nash-Equilibrium ist das Interaktionsergebnis, von dem kein Akteur abweichen kann, ohne sich selbst zu schaden. Voraussetzung dafür ist die vollständige Information über die Interessen und Handlungsmöglichkeiten aller Beteiligten. 3. Das Pareto-Optimum schlieBlich ist ein Interaktionsergebnis, das keinem beteiligten Akteur eine Verbesserung seiner Position ermöglicht, ohne einen anderen Akteur zu schädigen. (Ein kollektiv optimales Ergebnis, das in der utilitaristischen Vorstellung als ein wichtiges Gerechtigkeitskriterium gilt). Besonders interessant sind für Spieltheoretiker solche Spiele, in denen sich das Konzept der Rationalität in eine individuelle (Maximin- und Nash-Regel) und in eine kollektive Interpretation (Pareto) spalten. Dies wird dann als problematische soziale Situation beschrieben! Zu einer positiveren Beurteilung des Wertes spieltheoretischer Methoden für die historische Analyse kommen Hans MielanTs, Eric Mielants, The Importance of Simulation as a Mode of Analysis. Theoretical and Practical Implications and Considerations, in: Revue belge d'histoire contemporaine 27 (1997) 3/4 S. 293-322.

60 Uwe Jean Heuser hat den auch in den Wirtschaftswissenschaften einsetzenden Umdenkproze $B$ in einem längeren Artikel der Wochenzeitung Die Zeit beschrieben. Zunehmend geraten die in den siebziger Jahren gefeierten spieltheoretischen Deutungen wirtschafticher Entscheidungsprozesse in die Kritik. Statt dessen gewinnen die sogenannten "Verhaltensökonomen« an Deutungsmacht, die darauf hinweisen, daß rationales Abwägen nur einer von mehreren »Beratern« im Entscheidungsfindungsproze $B$ ist. Uwe Jean Heuser, Die Revolution hat begonnen. Auf Wiedersehen, homo oeconomicus, in: Die Zeit, 43 (2002), 17. Oktober 2002, S. 19 f. 
einen von vier idealtypischen Handlungsbegriffen. Neben dem zweckrationalen Handeln sollten Formen traditionalen, wertrationalen oder affektuellen Handlens als mögliche Alternativen sinnvollen Handelns von Spiel- und Wirtschaftstheoretikern ernster genommen werden ${ }^{61}$.

Auch Susanne Schmidt und Raymund Werle nehmen in ihrer Studie "Coordinating Technology« spieltheoretische Modelle in die Analyse von Standardisierungsprozessen im Bereich der Telekommunikationstechnik auf, bauen diese jedoch nur als ergänzende analytische Perspektive in ihren Ansatz des »akteurzentrierten Institutionalismus« ein. Ähnlich wie in der vorliegenden Arbeit geschehen, verbinden sie in ihren Fallstudien strukturelle und prozessuale Aspekte des Standardisierungsprozesses. Im Gegensatz zu den bereits vorgestellten Ansätzen liefert der "akteurzentrierte Institutionalismus « ein durchaus komplexes handlungstheoretisches Modell, in dem die subjektiven Freiheitsgrade der Akteure in einen die Handlungen strukturierenden, aber nicht unbedingt festlegenden Rahmen eingebettet werden:

The process of standardization is by no means the execution of a linear techno-logic. It is, rather, contingent on institutional factors, actor constellations, actors' interests and perceptions, technical knowledge, and what one might call the artifactual reference of the specific coordination problem. Hence, scrutinizing standardization is particularly suited to highlighting the social shaping of one significant stage in the generation of network technologies ${ }^{62}$.

Ist das von Schmidt und Werle vorgelegte Modell durchaus geeignet, dem Historiker die unterschiedlichen Dimensionen eines Standardisierungsprozesses vor Augen zu führen, reduzieren sich die vorgestellten Fallstudien (Videotext, Telefax, X.4000-Standard für elektronische Post) auf knappe und stark formalisierte Beschreibungen der im vorhinein definierten Systemfaktoren. Das durchaus komplexe Modell wird so, zumindest aus der Perspektive des Historikers, nicht mit Leben erfüllt, was gewisse SchluBfolgerungen schwer nachvollziehbar macht. Dies scheint aber eher das Resultat einer strukturellen Differenz zwischen soziologischer und historischer Arbeitsweise $\mathrm{zu}$ sein als das Resultat gezielter $»$ Komplexitätsreduktion ${ }^{63}$.

Da sich die Geschichtswissenschaft bisher selten mit handlungs- oder institutionentheoretischen Ansätzen beschäftigt hat, kann sie entsprechend wenig zur Unterfütterung diverser Standardisierungstheorien beitragen ${ }^{64}$. Eine Aus-

61 Max WeBER, Wirtschaft und Gesellschaft. GrundriB der verstehenden Soziologie, Tübingen 1922.

62 Schmidt, Werle, Coordinating Technology, S. 109.

63 Die Vernachlässigung der Erzählung zugunsten der Abstraktion erschwert die Nachvollziehbarkeit der gezogenen Schlüsse und macht die Lektuire der soziologischen Werke nicht immer zu einer wahren Lesefreude.

64 Entsprechend wenig ist von den theoretischen Ansätzen der diversen "rational-choice«-Ansätze in die geschichtswissenschaftliche Praxis eingeflossen. Ein Beispiel sozialhistorischer Standardisierungsforschung liefert Jean-Claude HocQUET, Harmonisierung von Maßen und Gewichten als Mittel zur Integrierung in Deutschland im 19. Jahrhundert, in: Eckart ScHREMmER (Hg.), 
nahme bilden hier neuere Arbeiten aus dem Bereich der Geschichte der internationalen Beziehungen, die sich - vor allem vor dem Hintergrund der nuklearen Bedrohungsszenarien - mit verhandlungstheoretischen Ansätzen und spieltheoretischen Modellen beschäftigt haben ${ }^{65}$. Wie Ursula Lehmkuhl nachgezeichnet hat, beginnt man seit einiger Zeit auch in der eher theoriefeindlich eingestellten klassischen Diplomatiegeschichte mit der Diskussion mentalitäts- oder kulturgeschichtlicher Fragestellungen, die - so die Hoffnung von Lehmkuhl -, dabei helfen können, die starre Dichotomie von Akteur und Struktur, von Mikro- und Makroperspektive aufzubrechen. In ihrem Aufsatz »Entscheidungsprozesse in der internationalen Geschichte: Möglichkeiten und Grenzen einer kulturwissenschaftlichen Fundierung außenpolitischer Entscheidungsmodelle« plädiert sie:

Ein kulturwissenschaftlich fundiertes entscheidungstheoretisches Modell muß das den klassischen politikwissenschaftlichen Ansätzen zugrundeliegende Menschenbild des homo oeconomicus durch die Annahme ergänzen, daß menschliches Handeln und Verhalten nicht allein rational im utilitaristischen Sinne begründet ist, sondern auch beeinflusst wird durch wenig veränderbare soziale und kulturelle Faktoren wie lebensweltliche Gemeinsamkeiten, Form der Kommunikationssituation, Stereotypen und damit verbundene Situationsinterpretation und nicht zuletzt auch Empathie $^{66}$.

Wirtschaftliche und soziale Integration in historischer Sicht, VSWG Beihefte 128, Stuttgart 1996, S. 110-123. Zur Kritik der »Theoriefeindschaft« auch im Bereich der historischen Sozialwissenschaft siehe die Einleitung von Thomas Welskopp und Thomas Mergel »Geschichtswissenschaft und Gesellschaftstheorie«, in: Thomas MERGEL, Thomas WelsKopP (Hg.), Geschichte zwischen Kultur und Gesellschaft. Beiträge zur Theoriedebatte, München 1997, S. 9-38. Beide Autoren werfen der Historischen Sozialforschung à la Wehler und Kocka vor, zwar in gewissem Umfange soziologischen Wortschatz (Habitus, Milieu) in ihre Darstellungen aufgenommen zu haben, doch: »Mit historischer Beißhemmung wurden Theorien >angewandt $<$ nicht verarbeitet $\ll$. Ibid.S. 20.

65 Siehe beispielhaft Michael J. Hogan, Thomas Paterson (Hg.), Explaining the History of American Foreign Relations, Cambridge, New York 1991. Der Band spiegelt die neueren Ansätze der Diplomatiegeschichte, in die - nach langem Abwehrkampf - nun auch mentalitätshistorische, kulturgeschichtliche und sozialpsychologische Fragestellungen aufgenommen werden. Aus politikhistorischer Sicht hat die amerikanische Politologin Rhonda Crane die europäische Farbfernsehkontroverse bereits 1979 untersucht. Rhonda J. CranE, The Politics of International Standards: France and the Color TV War, Norwood, New Jersey 1979.

66 Ursula LeHMKUHL, Entscheidungsprozesse in der internationalen Geschichte: Möglichkeiten und Grenzen einer kulturwissenschaftlichen Fundierung außenpolitischer Entscheidungsmodelle, in: Loth, Osterhammel (Hg.), Internationale Geschichte, S. 191. Referiert Lehmkuhl in dieser glänzenden Literaturübersicht den internationalen Stand einer kulturgeschichtlich fundierten Diplomatiegeschichte, baut sie ihre Ideen in dem Aufsatz »Diplomatiegeschichte als internationale Kulturgeschichte « zu einem mit leitenden Fragestellungen und methodischen Herangehensweisen ausgestatteten Forschungsmodell aus. Siehe DiEs., Diplomatiegeschichte als internationale Kulturgeschichte: Theoretische Ansätze und empirische Forschung zwischen Historischer Kulturwissenschaft und Soziologischem Institutionalismus, in: Geschichte und Gesellschaft 27 (2001) 3, S. 394-423. 
Neben dem in praktischer historischer Arbeit sicherlich nur schwer zu verwirklichenden Anspruch »ganzheitlicher« Betrachtung plädiert Lehmkuhl für eine Zurückdrängung des zweckrationalen zugunsten eines kommunikationstheoretischen Modells handlungstheoretischer Analysen. Damit neigt sie den von Anthony Giddens ${ }^{67}$ oder Pierre Bourdieu ${ }^{68}$ vertretenen Ansätzen zu, die zu einer Verknüpfung von Handlungs- und Strukturaspekten der Gesellschaft aufrufen ${ }^{69}$. Lehmkuhls Überlegungen decken sich in weiten Teilen auch mit

67 Anthony Giddens, Die Konstitution der Gesellschaft, Frankfurt a. M., New York 1995. In dieser Ausgabe liefert die Einleitung von Hans Joas "Eine soziologische Transformation der Praxisphilosophie - Giddens' Theorie der Strukturierung « eine knappe und prägnante Einführung in das Werk von Giddens. Für den Historiker besonders interessant ist der Aufsatz von Thomas WELSKoPP, Der Mensch und die Verhältnisse. "Handeln« und "Struktur« bei Max Weber und Anthony Giddens, in: Mergel, WelsKoPP (Hg.), Geschichte zwischen Kultur und Gesellschaft, S. 39-70. Siehe auch Thomas WeLSKopP, Die Dualität von Struktur und Handeln. Anthony Giddens' Strukturierungstheorie als "praxeologischer « Ansatz in der Geschichtswissenschaft, in: Andreas Suter, Manfred HetTling (Hg.), Struktur und Ereignis, Zeitschrift für Historische Sozialwissenschaft Sonderheft 19, Göttingen 2001, S. 99-119.

68 Pierte Bourdieu, Loïc J.D. Wacquant, An Invitation to Reflexive Sociology, Chicago 1992. Zu Bourdieus Konzept der »doppelten Reflexivität« siehe auch Ingrid GiLCHER-HoLTEY, "Kritische Ereignisse« und »kritischer Moment«: Pierre Bourdieus Modell der Vermittlung von Ereignis und Struktur, in: Suter, HeTtling (Hg.), Struktur und Ereignis, S. 120-137. Zur Bedeutung Bourdieuscher Denkansätze für die Geschichtswissenschaft siehe Sven REICHARDT, Bourdieu für Historiker? Ein kultursoziologisches Angebot an die Sozialgeschichte, in: MERGEL, WELSKOPP (Hg.), Geschichte zwischen Kultur und Gesellschaft, S. 71-94. Anregend für Historiker ist auch das Interview, das Lutz Raphael mit Pierre Bourdieu zum Thema Soziologie und Geschichte führte: Lutz RAPHAEL, Über die Beziehungen zwischen Geschichte und Soziologie in Frankreich und Deutschland. Pierre Bourdieu im Gespräch mit Lutz Raphael, in: Geschichte und Gesellschaft 22 (1996) S. 62-89. Eine Zusammenstellung für die Geschichtswissenschaft relevanter Aufsätze Bourdieus findet sich in Pierre Bourdieu, Schwierige Interdisziplinarität. Zum Verhältnis von Soziologie und Geschichtswissenschaft, hrsg. von Elke OHNACKER und Franz SCHULTHEIS, Münster 2004.

69 Lehmkuhl faßt ihre Position in einem 7-Punkte-Programm von Annahmen zusammen, die in ihren Augen für die kulturwissenschaftliche Fundierung geschichtswissenschaftlicher Forschung allgemein und eines kulturwissenschaftlich fundierten Entscheidungsmodells im besonderen von Bedeutung sind: 1. Ideen, Normen und Werte sind keine unabhängigen Variablen (psychologisches Modell), sondern können eigene Akteursqualitäten entwickeln und als intervenierende $\mathrm{Va}$ riablen in Entscheidungsprozessen wirken; 2. Giddens »doppelte Hermeneutik « muB beruicksichtigt werden (nicht nur Methode und Fragestellung beeinflussen Arbeitsresultate, sondern soziale Welt selbst wird darüber hinaus erst durch die Interpretation der Beteiligten konstruiert); 3. Da soziale Welt stets konstruierte Welt ist, können ihre Funktionsbedingungen nur mit Hilfe der verstehenden Methode, d.h. induktiv und nicht nomologisch-deduktiv erschlossen werden; 4. Das Verstehen von Handlungen erfordert nicht nur Ermittlung von Intentionen und Motiven der Akteure, sondern auch Rekonstruktion der Regeln, Normen, Kontexte, Milieus; 5. Kulturansätze weisen das rationalistische Menschenbild des »homo oeconomicus « zurück und setzen whomo sociologicus« entgegen. Menschen leben in einer symbolisch vermittelten Welt; 6 . Entscheidungen werden deshalb nicht aufgrund fixer Präferenzen und festgelegter Interessen getroffen, sondern diese können sich im Laufe des Interaktionsprozesses durch Reinterpretation der Kontexte verändern; 7. Da der Bedeutungsgehalt einer Handlung intersubjektiv gebildet wird, muB zur Erklärung des Zustandekommens einer Entscheidung die gemeinsam geteilte Sinnwelt erfaBt wer- 
dem von Thomas Mergel vorgelegten Konzept einer »Kulturgeschichte der Politik«. Ähnlich wie Lehmkuhl betont auch Mergel die Komplexität und symbolische Bedeutung der kommunikativen Konstruktion vergangener und gegenwärtiger Wirklichkeiten. Dem Historiker als Rekonstrukteur dieser Wirklichkeiten kommt nach Mergel die Aufgabe zu, »Interessen, Macht und Konflikte als kommunikativ produzierte und symbolisch repräsentierte Phänomene $\ll$ zu begreifen und zu analysieren ${ }^{70}$.

Es war das Ziel der als politische Kulturgeschichte der Technik untertitelten Studie, genau jene symbolische Dimension techno-politischen Handelns auf personeller und institutioneller Ebene herauszuarbeiten. In der PAL-SECAM-Kontroverse überlagern sich staatspolitische (Technik als »champion national« im Rahmen einer »politique de la grandeur «) und wirtschaftspolitische (PAL als »bestes« System »Made in Germany«) Symboliken, und die Verhandlungen im Rahmen der CCIR können als Arenen eines semantischen Kampfes um eine hochgradig politisierte Technik gedeutet werden. In der Tat haben wir es in Wien und Oslo mit »kommunikativen Verdichtungen ${ }^{71}$ eines techno-politischen Konfliktes zu tun, der unter narrativen Gesichtspunkten als Drama in zwei Akten interpretiert werden kann $^{72}$. Vor allem auf französischer Seite haben wir es mit einer meisterhaft orchestrierten diplomatischen Inszenierung zu tun, in der sämtliche politische Rhetorik und Macht aufgewandt wird, um den politischen "Gegner« zu schockieren (Veröffentlichung des französisch-sowjetischen Abkommens zwei Tage vor Beginn der Wiener Konferenz), zu irritieren (kurzzeitiges Angebot des NIR-Systems als französisches »Opfer« in Oslo) oder zu betören (falls man die Aufbesserung der Kassen der Democratia Christiana oder der Partito Socialista Italiana mit diesem Verb umschreiben kann...). Im Sinne der neueren Kulturgeschichte konnte man die CCIR-Verhandlungen in Wien und Oslo auch als »performances « beschreiben, in denen die unterschiedlichen Akteure in strategisch definierten $\gg$ Rollen « aufgetreten sind ${ }^{73}$. Keineswegs soll damit behauptet werden, daß die zentralen Akteure nach vorhersehbaren Mustern eines zuvor

den. Über die Sinnwelt der Akteure sind auch deren Motive und Intentionen zu erschließen. Lehmkuhl, Entscheidungsprozesse in der internationalen Geschichte, S. 195.

70 Thomas MERGEL, Überlegungen zu einer Kulturgeschichte der Politik, in: Geschichte und Gesellschaft, 28 (2002) S. 574-606, S. 594 f.

71 Ibid. S. 597.

72 Unter technikhistorischen Gesichtspunkten anregend ist hier der Beitrag von Bryan PFAFFENBERGER, Technological Dramas, in: Science, Technology \& Human Values 17 (1992) 3 S. 282-312. Generell zur "Drama-Analogie« in der Kulturgeschichte siehe BURKE, Was ist Kulturgeschichte, S. $56 \mathrm{ff}$.

${ }^{73}$ Siehe zum Thema performances Della Pollock (Hg.), Exceptional Spaces. Essays in Performance and History, Chapel Hill 1998; David M. Guss, The Festive State: Race, Ethnicity and Nationalism as Cultural Performance, Berkeley 2000; Doris BaChmann-Medick, Performative Turn, in: Dies. Cultural Turns, S. 104-143. 
festgelegten Drehbuches agiert hätten. Die mikroanalytische Beschreibung der Verhandlungssituation in Oslo hat gezeigt, wie flexibel das Rollenverhalten der Akteure in dem dynamischen Verhandlungsprozeß sein kann. Gerade diese prinzipielle Offenheit des historischen Augenblicks macht deutlich, wie problematisch die Reduktion der möglichen Handlungsoptionen aus posttheoretisierender Analyse ist. Ziel dieser Darstellung war nicht, den Standardisierungsproze $B$ in den unterschiedlichen Verhandlungssituationen einer Goffmanschen Rahmenanalyse zu unterziehen, dennoch drängen sich die Metaphern der »Bühne « und des »Theaters « auf, führt man sich die politische Inszenierung der Wiener und Osloer Verhandlungen vor Augen ${ }^{74}$.

Bereits 1965 hatte der »Adviser on Telecommunications and Transportation « im amerikanischen State Department, Paul F. Geren, erkannt, daß die Farbfernsehkontroverse ein "Musterbeispiel « interdependenter Entscheidungsstrukturen in den internationalen Beziehungen darstelle:

As in all technological change, how these facilities are arranged and coordinated belongs not only to the field of science but also to the area of international relations. Similarly, the arrangements between governments in the communications field influence for good or bad the freedom, the economy, and the efficiency of global communication. The choice of color television standards offers a dramatic illustration of this thesis ${ }^{75}$.

Zum wichtigen Hilfsmittel für das Verständnis internationaler Beziehungen, besonders wenn es sich um die Analyse diplomatischer Verhandlungen handelt, können sogenannte Verhandlungstheorien werden, die auf kommunikationstheoretischen Annahmen fußen. So macht Jon Elster in seinem Buch »Die Subversion der Rationalität« auf den wichtigen Unterschied zwischen öffentlichen und privaten Diskurssituationen aufmerksam ${ }^{76}$. Während bei öffentlichen Debatten die vorgetragenen Forderungen mit Hilfe von Argumentation untermauert würden, dominierten bei privaten Verhandlungen die klassischen »bargaining «-Mittel, nämlich Drohungen und Versprechen.

Thomas Saretzki hat auf der Basis der modernen Institutionentheorie (Göhler u.a. ${ }^{77}$ ), der Kommunikationstheorie (Habermas ${ }^{78}$ ) und Verhand-

74 In der Einleitung zu seiner Studie »Rahmen-Analyse» betont Goffman, daB es ihm um vor allem um die "Analyse von Betrug, Täuschung, Schwindelmanövern, verschiedenartigen Vorführungen« geht, und sich Presseartikel, populäre biographische Schilderungen oder auch Karikaturen besonders als Quellen des gesellschaftlichen "Theaters« eigneten! Erving GoFFMAN, Rahmen-Analyse. Ein Versuch über die Organisation von Alltagserfahrungen, Frankfurt a.M. 1980, S. $23 \mathrm{ff}$.

75 Paul F. Geren, Worldwide Standards for Color Television, in: United States, Department of State Bulletin, 53 (1965) S. 597.

76 Jon ELsTER, Die Subversion der Rationalität, Frankfurt a.M. 1987.

77 Einen Überblick über die moderne Institutionentheorie liefert Gerhard Göhler in seiner Einleitung zum Leviathan Sonderheft 16 (1996).

78 Eine Erweiterung des Habermasschen Ansatzes findet sich bei Dietrich BöHLER, Rekonstruktive Pragmatik. Von der Bewußtseinsphilosophie zur Kommunikationsreflexion: Neubegründung 
lungstheorie (Elster) ein verhandlungstheoretisches Modell entwickelt, dessen zentrale These lautet: »Der Kommunikationsmodus >Argumentieren< korreliert mit einer relativ hohen Stabilität der getroffenen Entscheidung und weist darüber hinaus wegen des damit verbundenen moralischen Rekurses auf Inhalte des >common good eine hohe Implementationswahrscheinlichkeit auf ${ }^{79}$. Übertragen auf die Farbfernsehkontroverse könnte dies bedeuten: Der wirtschaftlich-technisch motivierte Kommunikationsmodus »arguing « mit moralischem Rekurs auf das »common good « (= einheitlicher europäischer Standard) wies eine hohe Implementationswahrscheinlichkeit auf. Der außenpolitisch motivierte Kommunikationsmodus »bargaining « der französischen Seite mit dem klassischen Überzeugungsrepertoire "Drohungen und Versprechungen« stieß auf Widerstand der technisch-wissenschaftlichen Experten des CCIR. PAL war dort erfolgreich, wo der Boden für »Argumentation« fruchtbar war, das heißt auf technisch-wirtschaftlichem terrain. SECAM war dort erfolgreich, wo der Boden für »Verhandeln« fruchtbar war, das heißt auf politischem terrain.

Scheint dieses Modell auf die Farbfernsehkontroverse zu "passen«, erklärt es dennoch nicht die strukturellen Rahmenbedingungen und die persönlich, kulturell, wirtschaftlich oder politisch gefärbten Motivationen der Akteure. Ruft man sich die Komplexität der Verhandlungssituationen in Wien oder Oslo ins Gedächtnis, so scheint es unwahrscheinlich, daß eine der bislang vorgestellten Theorien eine auch nur annähernd exakte Beschreibung der realen historischen Verhältnisse erlaubt. Insofern schließt sich der Autor dem hermeneutischen Befund von Ursula Lehmkuhl an, daß in einem ersten Schritt eine möglichst mikroskopische Rekonstruktion der Ereignisgeschichte die Details eines Entscheidungsprozesses aufzeigen sollte. Erst wenn der Historiker sich ein möglichst umfassendes »Vorverständnis« über die Geschehensabläufe angeeignet hat, so Lehmkuhl, sollten analytische Modelle zur Systematisierung oder Verfeinerung der geschichtswissenschaftlichen Interpretation herangezogen werden. Auf der Grundlage dieser Erkenntnisse muB dann im Sinne von Giddens' »doppelter Hermeneutik« die Ereignisgeschichte reinterpretiert werden. Ohne diese Kombination detaillierter historischer Rekonstruktion und reflexiver Interpretation wäre es kaum möglich, die von Degenhardt und Strautz beschriebenen Irritationen des "sozialen Habitus«

der praktischen Wissenschaften und Philosophie, Frankfurt a.M. 1985. Im AnschluB an Apel und Habermas, denen das Buch auch gewidmet ist, vollzieht Böhler eine pragmatisch-hermeneutische Wende, die durch den Verpflichtungsgehalt des Argumentierens vor dem Relativismus gefeit sein will. Philosophie wird in diesem Sinne als Ethik des öffentlichen Dialogs verstanden.

79 Thomas SARETZKI, Wie unterscheiden sich argumentieren und verhandeln? Definitionsprobleme, funktionale Bezüge und strukturelle Differenzen von zwei verschiedenen Kommunikationsmodi, in: Volker von PrITTwTz (Hg.), Verhandeln und Argumentieren. Dialog, Interessen und Macht in der Umweltpolitik, Opladen 1996, S. 19-40. 
der technischen Akteure der CCIR zu verstehen, die durch die Politisierung technischer Entscheidungsfindungsprozesse entstanden sind ${ }^{80}$.

Auf die Frage, ob es sich bei dem »large technological system « Farbfernsehen denn nun um eine sozial konstruierte Auseinandersetzung oder um eine von technisch-wirtschaftlichen Rationalitäten geprägte Debatte handelte, hat Thomas P. Hughes im übertragenen Sinne bereits 1987 in den ersten zwei Sätzen seines bekannten Aufsatzes »The evolution of large technological systems« eine salomonische Antwort gegeben: »Technological systems contain messy, complex, problem-solving components. They are both socially constructed and society shaping «

80 Degenhardt, Strautz, Auf der Suche nach dem europäischen Programm. Auch wenn der Vergleich etwas überzogen scheinen mag, könnte man die Bedeutung des von Degenhardt und Strautz beschriebenen sozialen Habitus der Techniker und Ingenieure bei der Herstellung eines Standards mit der von Steven Shapin so brillant analysierten Bedeutung sozialer und kultureller Normen bei der Herstellung einer wissenschaftlichen Tatsache im England des 17. Jahrhunderts vergleichen. In beiden Fällen generiert sich die Autorität der am Verhandlungsproze $B$ beteiligten Akteure durch einen gewissen Status, auch wenn dieser im 17. Jahrhundert vor allem sozialer Natur war (Mitglied der adligen Oberschicht), und nicht politischer oder wissenschaftlicher $\mathrm{Na}$ tur, wie dies bei den Mitgliedern der CCIR-Delegationen der Fall war. Steven SHAPIN, A Social History of Truth: Civility and Science in Seventeenth Century England, Chicago 1994.

81 Hughes, The evolution of large technological systems, S. 51. 


\subsubsection{Der Mythos vom »besten System « und dem "genialen Erfinder"}

Die historische Rekonstruktion der Farbfernsehkontroverse bis zum Scheitern der Standardisierungsbemühungen im Juli 1966 läßt aus technikhistorischer Perspektive keinen anderen SchluB zu, als daß die konkurrierenden Alternativen technisch gleichwertige Systeme darstellten. Ein Blick in die populärwissenschaftliche wie fachwissenschaftliche Literatur, die nach dem Scheitern der Standardisierungsbemühungen erschienen ist, suggeriert dem Leser jedoch ein ganz anderes Bild. Sowohl in deutschsprachigen wie auch in französischsprachigen Publikationen wird bereits 1966 mit der Konstruktion von Mythen begonnen, die dem PAL- bzw. SECAM-System technische Überlegenheit über das jeweils andere Verfahren andichten.

Groß war daher die Aufregung bei Telefunken, als ein »Spiegel«-Artikel mit der Überschrift »Legende gehäkelt« im März 1969 am PAL- bzw. BruchMythos kratzte, in dem Bruchs erfinderische Leistung bei der Entwicklung des PAL-Systems in Frage gestellt wurde:

Vier Jahre lang galt das von Telefunken Anfang 1965 öffentlich vorgestellte PAL-Farbfernsehsystem als Musterbeispiel nachkriegsdeutschen Technikruhmes. Nun aber erweist sich, was >Bild am Sonntag` 1967 stolz die stollste Färberei der Welt` nannte, zum guten Teil als Schönfärberei. Die Branchenkonkurrenz, seit längerem insgeheim über Telefunkens werbeträchtigen PAL-Nimbus vergrämt, möchte das Image des sgenialen Erfinders Bruch (AEG-Telefunken Pressesprecher Friedrich Bender) nicht länger unangetastet lassen ${ }^{82}$.

Tatsächlich hatte Telefunken - aus unternehmerischer Perspektive nachvollziehbar und legitim - mächtig mit Bruchs Image als »Mr. PAL« und »Vater des Farbfernsehens« für seine Farbfernsehempfänger geworben. Dementsprechend scharf fiel die schriftliche Reaktion Telefunkens aus. In einem sechsseitigen Schreiben an »Spiegel«-Chefredakteur Engel wandte sich Telefunken Pressesprecher Bender gegen die vom »Spiegel« geäußerten Vorwürfe. Intern waren sowohl Walter Bruch als auch der Leiter der Telefunken-Patentabteilung, Dr. Johannesson, aufgefordert worden, zu den "Spiegel«-Vorwürfen Stellung zu nehmen. In einem Brief vom 17. März 1969 an den Leiter des Instituts für Rundfunktechnik in München, Prof. Richard Theile, bekannte Bruch:

Ich kann mir einfach nicht vorstellen, daß es irgendeinen Menschen gibt, der Grund hätte, einen solchen Angriff gegen meine Person zu richten, auch nicht der, der sich sonst nicht gerade sehr wohlwollend mir gegenüber geäußert hat. Dies Haltung traue ich einfach niemandem zu. Weni-

82 N.N.: Legende gehäkelt, in: Der Spiegel, 10.03.1969, S. 182. 


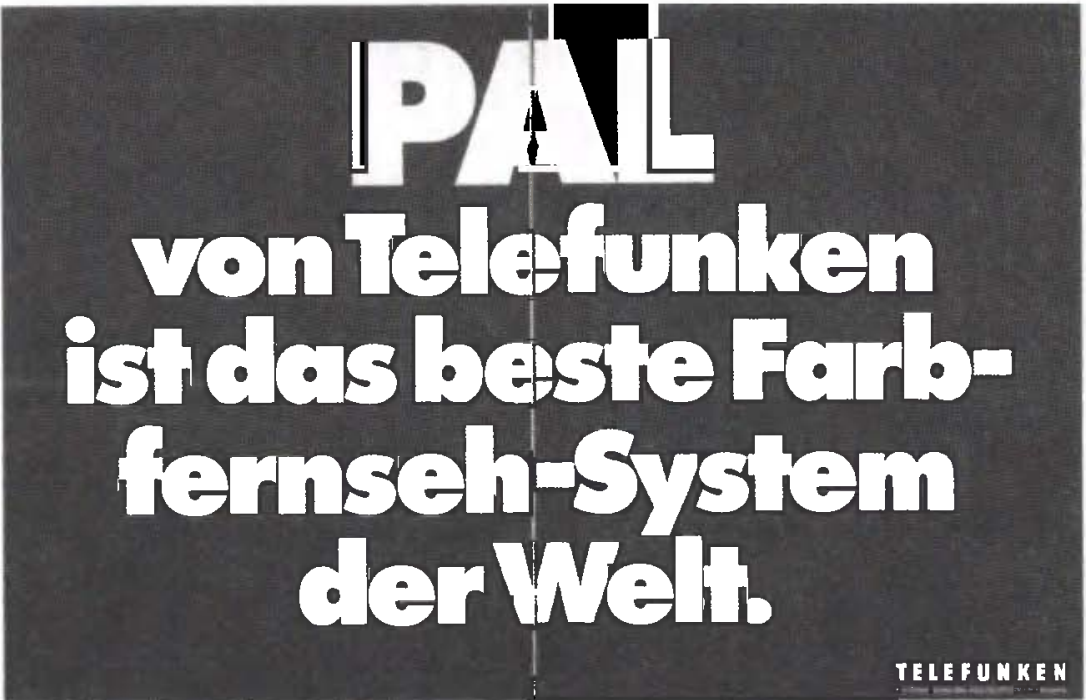

Telefunken. Erfe/hren im Erfinden.

Abb. 27: „Das beste Farbfernsehsystem der Welt«. Telefunken Werbung im »Spiegel" vom 10. März 1969, aus: Archiv des Deutschen Museums München, Nachlaß Walter Bruch, Signatur NL 101, Nr. 269.

ger als über die Sache grüble ich Tag und Nacht darüber nach, wer könnte dieser Mensch sein und was könnte der Anlaß dazu $\operatorname{sein}^{83}$ ?

Doch schon vor diesem Schreiben war die »Trias« der deutschen Fernsehtechnik, bestehend aus Dr. Hans Rindfleisch (Technischer Direktor des NDR), Dr. Johannes Müller (Oberpostrat und Farbfernsehexperte des Fernmeldetechnischen Zentralamtes (FTZ) in Darmstadt) sowie Prof. Theile selbst, Walter Bruch in Form einer offiziellen Stellungnahme zu Hilfe geeilt. In einem Brief vom 17. März 1969 bat Hans Rindfleisch den Herausgeber des »Spiegel «, Rudolf Augstein, um die Veröffentlichung folgender Stellungnahme, die von allen drei oben genannten unterzeichnet war:

Wir sind besorgt, daß die Leistungen von Walter Bruch für die Entwicklung der Farbfernsehtechnik in ein schiefes Licht geraten. Die Bedeutung der Arbeiten von Bruch liegt darin, daB er ein in der amerikanischen Fachliteratur erörtertes Prinzip zum Ausgleich von Farbfehlem [das sogenannte Prinzip der "Color Phase Alternation« des Hazeltine-Ingenieurs Bernard Loughlin, A.d.V.] unter Ḧinzufugung eigener Erfindungen weiterentwickelt und damit für die Technik moderner Farbfernsehempfänger anwendbar gemacht hat. Aus jahrelanger Zusammenarbeìt fühlen sich die Unterzeichneten, die im Bereich der Deutschen Bundespost und der Rundfunkanstalten bei der Vorbereitung des Farbfernsehens mitgewirkt haben, zu der Erklärung verpflichtet, daß

83 Brief von Walter Bruch an Richard Theile, Hannover, 17.03.1969, 6 maschinegeschriebene Seiten, hier S. 6, in: Archiv des Deutschen Museums München, Nachlaß Walter Bruch, Signatur NL 101, Nr. 178. 


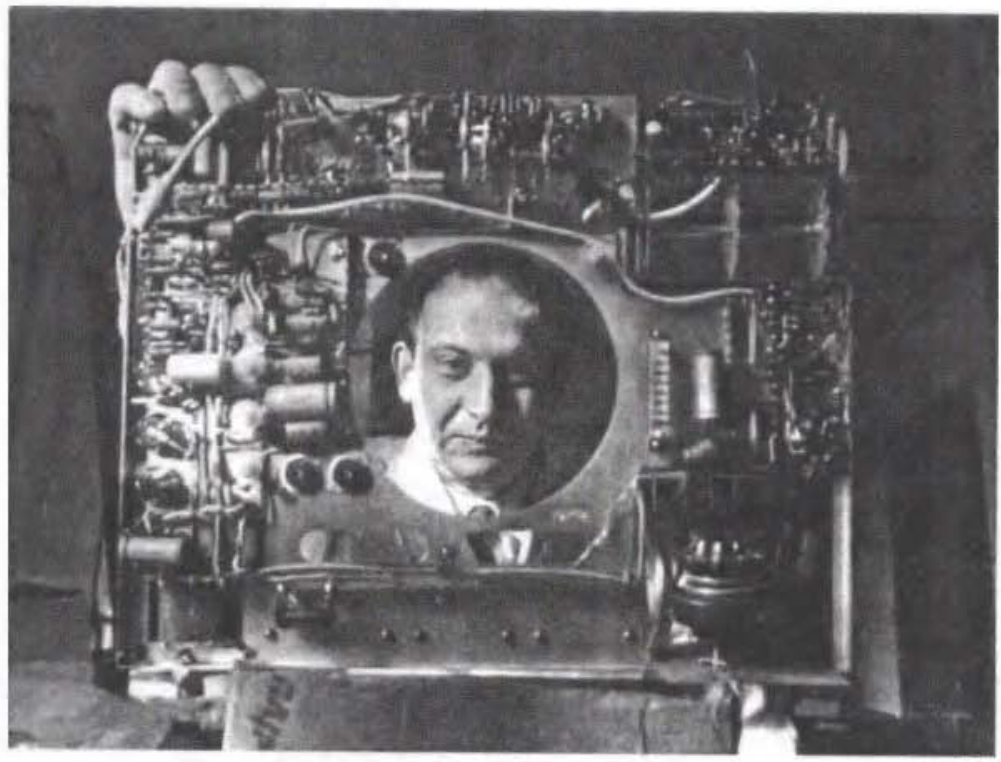

Abb. 28: "Henri de France lors de la creation du SECAM«, Nachruf Henri de France in französischer Zeitung, aus: Archives du CHTV/NA, Nachlaß Michel Dubail.

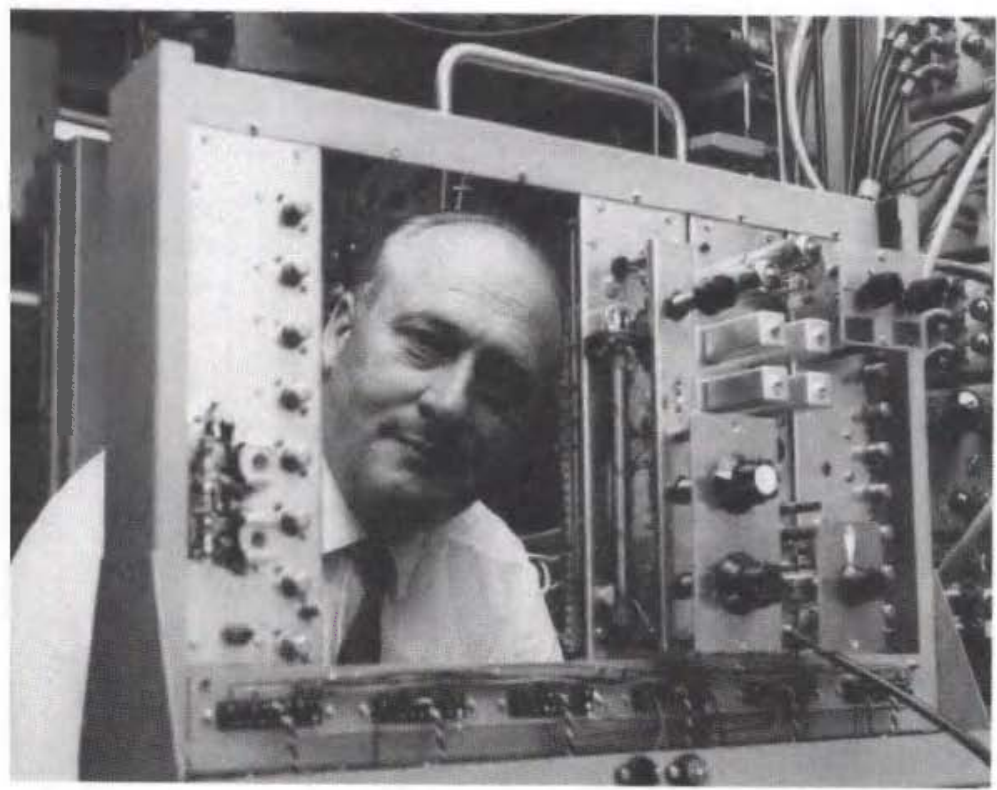

Abb. 29: Walter Bruch Werbephoto von Telefunken, aus: Archiv des Deutschen Museums München, Nachlaß Walter Bruch, Signatur NL 101, Nr. 270. 
Bruch die Fachleute im In- und Ausland allein durch die Ergebnisse seiner technisch-wissenschaftlichen Entwicklungsarbeit überzeugt hat. Seine Leistung sollte unangetastet bleiben und nicht von Diskussionen über Patent- und Lizenzfragen überschattet werden ${ }^{84}$.

Im Anschreiben zu der Kopie der »Ehrenerklärung«, die Rindfleisch am gleichen Tag an Walter Bruch schickte, machte dieser Bruch Mut und gab zu Bedenken, daß diese Stellungnahme das Bild bei einigen Leuten, »auf die es ankommt «, wieder zurechtrücken werde: "Im übrigen sollte man sich derartige Artikel im >Spiegel nicht allzusehr zu Herzen nehmen. Im >Spiegel< angegriffen zu werden«, so Rindfleisch tröstend, "gehört nun einmal zu den Attributen der Prominenz « ${ }^{85}$.

Auch in der DDR versuchte man 1974 am PAL-Mythos bzw. Bruch-Mythos zu kratzen. Doch die recht scharfen Attacken des Chefredakteurs der Fachzeitschrift »Radio Fernsehen Elektronik« verhallten in der Bundesrepublik mangels Publizität ziemlich lautlos ${ }^{86}$.

84 Brief von Dr. Hans Rindfleisch an Rudolf Augstein, Hamburg, 17.03. 1969, in: Archiv des Deutschen Museums München, NachlaB Walter Bruch, Signatur NL 101, Nr, 178.

85 Ibid.

86 Selbst schärfere Geschütze, wie sie in einem 1974 erschienenen Artikel mit der Überschrift »Neutraler Techniker?« der ostdeutschen Zeitschrift »Radio Fernsehen Elektronik« von RFE-Redakteur Schätter aufgefahren wurden, sorgten nicht für ernsthafte Irritation. Anders als im »Spiegel«-Artikel ging es dabei nicht um die technischen Verdienste Bruchs am Farbfernsehen, sondern um eine kritische Auseinandersetzung mit einem von Bruch selbst in der Zeitschrift »Funkschau« veröffentlichten Artikel »Peenemünde 1942: Die Anfänge des Industriefernsehens«. Dieser Artikel, eine verschriftlichte Fassung eines Vortrages von Bruch, den dieser auf Einladung der Hermann-Obert-Gesellschaft während der Funkausstellung in Berlin gehalten hat, ist in seiner naiven Bewunderung für die Leistungen der Technik im Rahmen des nationalsozialistischen Vernichtungskrieges ein erschreckendes Selbstzeugnis des Bruchschen Selbstverständnisses als »neutraler Techniker«. Einige Auszilge aus dem Artikel mögen diese These unterstreichen: »Wir Pioniere, die wir unser bisheriges Leben der technischen Entwicklung des Fernsehens gewidmet hatten, versuchten alles, um auch im Kriege an der Fernsehtechnik weiterforschen zu können. Heute noch kommt es mir wie ein Wunder vor, daß es gelang, sofort das Luftfahrtministerium für das Fernsehen zu interessieren. [...] Damals gehörte ich zu denen, die glaubten, der Krieg sei in wenigen Wochen vorbei [...] und dann wollte ich eine kleine zivile Wunderanlage für Reportagen haben. [...] Kurz vor dem Start [der A 4-Rakete, A.d.V.] wurden die Menschen vom Gelände gescheucht, die Gefangenen, deren man sich für Hilfsarbeiten bediente, waren in ihre Baracken gesperrt. [...] Ich war noch jung und stolz, so mächtigen Leuten wie Speer oder Himmler, dem Gefürchteten, etwas erzählen zu können. [...] Gigantisch muß das Erlebnis des ersten gelungenen Abschusses auf Dr. von Braun, Generalmajor Dornberger und ihre Mitarbeiter gewirkt haben, als ihre >Kinder` von ihrem Willen gelenkt, sich selbständig machten. Für mich war das Gefuhl, über Fernsehen dabei gewesen zu sein, mindestens genau so gewaltig [...] mindestens ein solches Wunder wie später die ersten Fernsehbilder vom Menschen auf dem Mond. [...] Peenemünde war die Geburtsstunde dessen, was wir heute ganz allgemein Industriefernsehen nennen [...] Und das ist etwas, was historisch festgehalten werden sollte«. In aller Deutlichkeit kritisierte Schätter Walter Bruch in einer Replik und forderte ihn auf, zwischen »neutraler Technik « und der Verantwortung des Technikers für den Einsatz von Technik zu unterscheiden: "Wenn die SS zufällig daran interessiert gewesen wäre, die qualvolle Ermordung ihrer Opfer in den Gaskammern von Maidanek und Auschwitz über ein System industriellen Fernsehens zu be- 
Die Mythisierung der Genialität des Erfinders fand im benachbarten Frankreich in durchaus ähnlicher Weise statt. Hier war es die Person von Henri de France, die ins Zentrum der Aufmerksamkeit rückte. Defrance, wie er sich in jungen Jahren schrieb, hatte sich durch eine kleine Namensänderung bereits selbst nobilitiert und verkörperte in der Öffentlichkeit das Bild des begnadeten Tüftlers und Bastlers. Ob 819-Zeilensystem, SECAM oder spätere Erfindungen wie das »Fluoskop«, eine Apparatur zur Beobachtung präparierter fluoreszierender Mikroorganismen, immer war er - so Jacques Parrot in einem Nachruf im Jahre 1980 - seiner Zeit voraus ${ }^{87}$ !

Die Werbung für das SECAM-System transportierte sich in Frankreich aber weniger über die Person von Henri de France als über staatlich organisierte Wege. Eingeläutet wurde die Phase der verstärkten »promotion du SECAM « durch den Einstieg von Sylvain Floirat als Gesellschafter der CFT Ende 1965. Entscheidend beschleunigt und intensiviert wurden die staatlichen Aktivitäten aber erst nach der Benennung Simon Noras zum neuen "Délégué interministériel« am 13. Oktober 1967 durch Premierminister Georges Pompidou ${ }^{88}$. Unter seiner Leitung kam es Ende 1967 zur systematischen Arbeitsteilung zwischen den staatlichen, halbstaatlichen und privat-

obachten, berechtigt in diesem Artikel nichts zu der Hoffnung, daß sein Autor ein derartiges System nicht in die Gaskammern eingebaut und nicht 30 Jahre später in einer westdeutschen Fachzeitschrift beschrieben hätte - und daß diese ihn nicht veröffentlichen würde. [...] Von der Bildröhre, auf der der Start der V 2 beobachtet werden konnte, verlangt man keine Stellungnahme zu dem verbrecherischen Krieg, dem diese Beobachtung diente - wohl aber von dem Mann, der sie installierte und mit seinen Geräten die Beobachtung ermöglichte«. Da es sich bei der Zeitschrift »Radio Fernsehen Elektronik um eine ostdeutsche Fachzeitschrift handelte, sorgte dieser Angriff auf das Image von Walter Bruch in der Bundesrepublik für wenig Aufsehen, da lediglich ein geringer Leserkreis von Radio- und Fernsehspezialisten im Westen erreicht wurde. SCHÄFFER, Neutraler Techniker?, in: radio fernsehen elektronik 23 (1974) 11.

87 Sogar das 819-Zeilensystem wird als weitsichtige Vorwegnahme des HDTV-Fernsehens interpretiert: "On n'épilogera pas sur le destin final du 819, ni sur les conséquences de son adoption sur un certain retard de développement de la télévision française. La vérité est qu'une fois de plus, en avance sur son temps, Henri de France avait vu juste sur l'avenir de la haute définition «. Jacques PARrot, Apres le $\$ 819$ lignes et le SECAM, Henri de France inventait le fluoscope, Zeitungsartikel - wahrscheinlich April 1980, in: Archives du CHTV/INA, NachlaB Michel Dubail.

${ }^{88}$ Die Nachfolger François de Laboulays im Amt des „Délégué interministériel«, Jean-François Deniau und Biasini, hatten in den Augen Noras die notwendigen Koordinationsaufgaben nur unzureichend ausgefuhtrt. Nora plädierte für eine gezieltere staatliche Aktion, um die SECAM-Affäre zu einem letztlich vorteilhaften Geschäft für den französischen Staat zu machen. »Un tel arbitrage est nécessaire«, so Simon Nora in einer 13-seitigen »Note sur la promotion du SECAM a l'étranger «, "notamment, pour qu'il soit mis fin à la confusion dans laquelle s'est poursuivie jusqu'à présent la promotion du SECAM: celle-ci a été conduite plutôt au gré des évènements qu'en vertu d'un plan prétabli, et sans que le partage des initiatives et des responsabilités, notamment financières, ait jamais été clairement décidé. [...] Cette façon de procéder ne peut plus être poursuivie dans l'avenir«. In: Archives du MAE, Affaires Économiques et Financières, Affaires Générales, Nr. 926. Aus diesen Sätzen spricht der Geist der "planwirtschaftlichen Elite«, zu der 
wirtschaftlichen Akteuren, die an der SECAM-Vermarktung beteiligt wa$\mathrm{ren}^{89}$. In einer 13 seitigen Skizze über die in den Augen Noras dringend notwendige Neustrukturierung der SECAM-Aktivitäten sparte dieser nicht mit Kritik an der bisherigen »Zersplitterung der Akteure « und »Verschwendung von Krediten« und forderte eine konzentrierte, staatlich geführte SECAMPropagation:

Il n'est pas besoin de rappeler longuement que l'affaire du SECAM comporte une dimension proprement politique. C'est un fait que, dès l'origine, un certain aspect du prestige français a été délibérément engagé dans le lancement du SECAM. [...] Le fait que l'enjeu essentiel de la promotion du SECAM soit de nature politique comporte une conséquence importante: c'est que les chances de cette promotion dépendent très étroitement de l'ampleur des efforts que l'État sera ou non disposé à consentir à sa faveur ${ }^{90}$.

sich Nora nach eigenen Aussagen zählte. Allerdings sollte sich Nora später sehr kritisch mit seiner Funktion als Technokrat auseinandersetzen. Siehe Simon NorA, Servir l'Etat, S. $102 \mathrm{ff}$.

${ }^{89}$ Anfang 1968 wurden die SECAM-Aktivitäten wie folgt aufgeteilt: Die CFT gab sämtliche technisch-industrielle Aktivität auf und mutierte zu einer reinen SECAM-Patentverwaltungsgesellschaft. Die Lizenz zur Produktion transistorisierter SECAM-Empfänger wurde von der CFT an die Société Électronique Moderne de l'Oise (EMO) vergeben, deren Hauptaktionäre Floirat und de France waren. Dafür mußte sich die EMO verpflichten, Teile des Personals der CFT zu übernehmen. Die vereinbarte Lizenzgebühr, welche die EMO an die CFT zu zahlen hatte, betrug 5 Francs pro verkauftem Empfänger. Zusätzlich zahlte die EMO der CFT eine einmalige Abfindung von 300000 Francs in bar. Die gesamte Produktion im Bereich des professionellen Fernsehmaterials (Studio- und Sendetechnik, Verzögerungsleitung etc.) wurde in Lizenzvereinbarung mit der CFT von der CSF hergestellt. Auch die CSF übernahm einen Teil des technischen Personals der CFT (68 Personen). Ausgenommen von diesem Abkommen war die Produktion der Farbröhre, für die eine eigene Firma mit dem Namen France Couleur gegründet wurde. Hauptaktionär von France Couleur, an der die CFT mit 10\% des Kapitals beteiligt war, war wiederum Sylvain Floirat. Der Staat beteiligte sich an der Entwicklung der neuartigen Farbröhre in Form einer Subvention in Höhe von 40 Millionen Francs, von denen France Couleur im Falle einer erfolgreichen Vermarktung maximal 10 Millionen zurückzahlen mußte. Schließlich wurde die Arbeit der 1965 gegründeten staatlichen Gesellschaft zur SECAM-Werbung FRANTECO am 1. Januar 1968 durch die neue Gesellschaft INTERSECAM ersetzt. INTERSECAM hatte zur Aufgabe, »de poursuivre les efforts pour la promotion dans les pays tiers du SECAM et des techniques françaises de télévision en couleur. A cette fin, il assure une action permanente d'information générale et des actions particulières pays par pays«. Obwohl auch INTERSECAM durch staatliche Zuschüsse gefördert wurde, wurden die laufenden Kosten, die jährlich mit $600.000 \mathrm{FF}$ beziffert wurden, zu 30\% von der CFT, zu 20\% von der ORTF und zu 50\% von der Fédération Nationale des Industries Electroniques (FNIE) getragen. Es handelte sich demnach um eine eher privatwirtschaftlich initiierte Organisation zur SECAM-Werbung im Ausland. Als Präsident von INTERSECAM wurde Paul-Roger Sallebert, als Generaldirektor André Pons benannt. Die Nachfolge von Sallebert trat später der CFT-Direktor Michel Dubail an. Das Kapitel »bataille du SECAM « würde eine eigene Darstellung erfordem, kann aber an dieser Stelle nicht geleistet werden. Zu der SECAM-Promotion in der Pompidou-Ära siehe FICKERS, »Pourquoi ne feraient-ils pas un procès a Telefunken?«.

90 Simon Nora, Note sur la promotion du SECAM à l'étranger, 13 maschinegeschriebene Seiten, hier S. 4, in: Archives du MAE, Affaires Économiques et Financières, Affaires Générales, Nr. 926. 


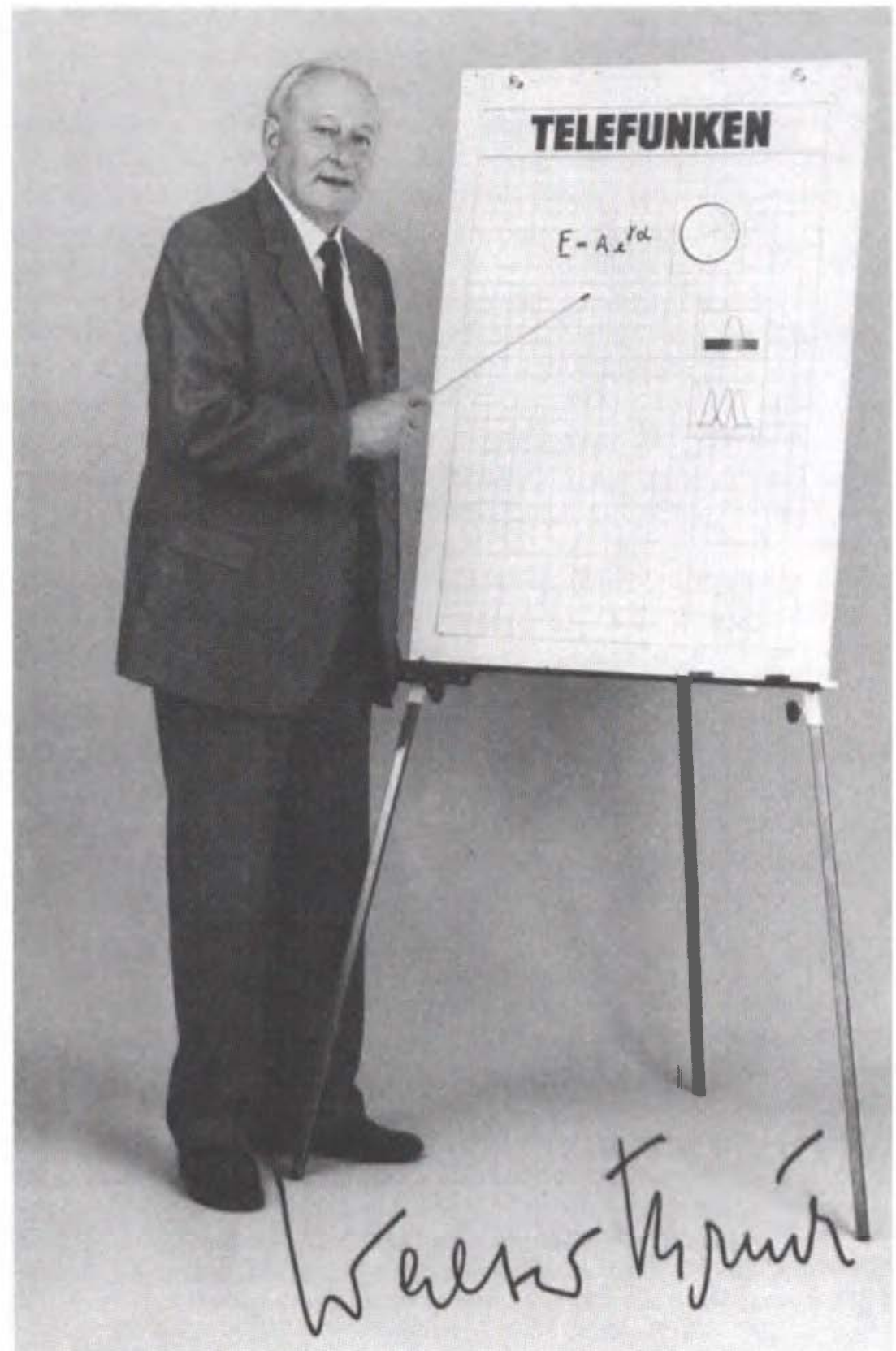

Abb. 30: Der. Einstein der Fernsehtechnik? Walter. Bruch Autogrammkarte, aus: Archiv des Deutschen Museums München, Nachlaß Walter. Bruch, Signatur NL 101, Nr. 269. 
Die konzentrierte staatliche Aktion war laut Nora um so dringender, da das »Prestige der deutschen Technik « in vielen noch unentschlossenen Ländern die Einführung des SECAM-Systems dort erheblich erschwere.

Wie diese Beispiele zeigen, bemühte man sich auf deutscher wie auf französischer Seite, die angeblichen Vorteile des eigenen Systems publizistisch zu vermarkten und ihm gegebenenfalls mit politischer Schützenhilfe zur Einführung in Drittländern zu verhelfen. Ihm Rahmen dieses Wettlaufs wurden die beiden »system builder« Henri de France und Walter Bruch zu »Helden der Technik « stilisiert, deren Image als »geniale Erfinder" gezielt zu Werbezwecken eingesetzt wurde. Zwar gab es sowohl auf französischer wie auf deutscher Seite vereinzelte Versuche, diesen Mythisierungsversuchen entgegenzutreten, doch verhallte die Kritik meist ungehört. Aus mentalitätshistorischer Perspektive zeugt diese Mythenbildung von der erfolgreichen Verschmelzung privater und nationaler Erfolgsgeschichten: Auf bundesdeutscher Seite kommt es zur Verschmelzung des »Bruch-Mythos« mit der Erfolgsgeschichte des »bundesdeutschen Wirtschaftswunders«; auf französischer Seite wurde der »champion national « SECAM zum Symbol der »politique de la grandeur « und der »trente glorieuses«. Im Sinne von Robert Frank symbolisieren somit beide Erfolgsgeschichten die »gelungene« Bewältigung der nationalen Identitätskrisen, welche Deutschland und Frankreich nach dem Zweiten Weltkrieg durchzustehen hatten ${ }^{91}$. Beide Systeme stehen stellvertretend für ein wiedergewonnenes technopolitisches Selbstbewußtsein beider Staaten und spiegeln gleichzeitig die unterschiedlichen Wege oder Strategien, die auf beiden Seiten des Rheins im Rahmen des Modernisierungsprozesses nach 1945 eingeschlagen wurden.

\subsubsection{Für eine politische Kulturgeschichte der Technik}

Die vorliegende Untersuchung der Debatte um die Einführung eines einheitlichen europäischen Farbfernsehstandards zielte darauf, die in diesen Entscheidungsfindungsproze $B$ eingebundenen Akteure sowie die ihn einrahmenden institutionellen Kontexte in einer mehrdimensionalen historischen Erzählung zu rekonstruieren und analysieren. Als leitende Fragestellungen dienten dabei technikhistorische, wirtschaftshistorische und politikhistorische Ansät-

91 In seinem Aufsatz "Mentalitäten, Vorstellungen und internationale Beziehungen « analysiert Robert Frank das "Syndrom von Vichy" in Frankreich. Die Kapitulation habe im Nachkriegsfrankreich ein tiefempfundenes Bedürfnis nach Modernisierung (wirtschaftlich) und nach einer wirksamen Verteidigung geschaffen. Ohne dieses Syndrom sei die Ablehnung der EVG nicht zu verstehen, genausowenig wie de Gaulles "politique de la grandeur«. In Deutschland sei das "Syndrom Stunde Null« Ausdruck dieser nationalen Identitätskrise gewesen. Die bundesdeutsche Antwort auf diese Krise sei das "deutsche Wirtschaftswunder" gewesen. Frank, Mentalitäten, Vorstellungen und internationale Beziehungen, in: LOTH, OSTERHAMmEL (Hg.), Internationale Geschichte, S. 159-185. 
$z e$, die in einer gezielten Kombination und durch eine kulturgeschichtliche Perspektive erweitert in einen Ansatz münden sollten, der als politische Kulturgeschichte der Technik vorgestellt wurde. Aus Sicht des Autors hat sich diese mehrdimensionale Herangehensweise in mehrfacher Weise bezahlt gemacht. Der historische Vergleich der bundesdeutschen und französischen Entwicklungsgeschichte des Farbfernsehens erforderte die Herausarbeitung von vier Vergleichsebenen: einer technischen, einer institutionellen, einer wirtschafts- und industriepolitischen sowie einer allgemeinpolitischen Ebene. Die Einbettung dieser unterschiedlichen thematischen Ebenen in die jeweiligen nationalen Kontexte ermöglichte es, die strukturellen Differenzen zwischen beiden Ländern herauszuarbeiten, die für das Verständnis der Farbfernsehkontroverse unabdingbar waren. Die strukturellen Differenzen und ihre Auswirkungen auf den Verlauf der PAL-SECAM-Kontroverse lassen sich in sechs zentralen Punkten zusammenfassen:

1. Die unterschiedliche politische Verankerung bzw. institutionelle Formgebung des Rundfunks in beiden Ländern. Während der Rundfunk in Frankreich bis Ende der siebziger Jahre eng mit regierungspolitischen Entscheidungsbefugnissen verknüpft bleibt - die ORTF ist dem Informationsminister direkt unterstellt -, führt die von den Alliierten Besatzungsmächten in Deutschland eingeführte föderale Organisation des Rundfunks (Landesrundfunkanstalten) zur erfolgreichen Abwehr bundespolitischer Interessen.

2. Diese Differenz spiegelt sich auch in den rundfunktechnischen Entscheidungen beider Länder. Während in Frankreich schon die Einführung des 819-Zeilenstandards das Resultat einer industriepolitischen Entscheidung war (Protektion der schwachen französischen Rundfunkindustrie durch Wahl eines eigenen Standards), setzt man in der Bundesrepublik früh auf die Harmonisierung der Fernsehnormen, um sowohl den Programmaustausch möglich zu machen als auch die Exportchancen der starken Rundfunkindustrie zu fördern.

3. Ist die französische Rundfunkindustrie somit direkt in die Strategie planwirtschaftlich organisierter Modemisierung des Landes eingebunden, fehlen in der Bundesrepublik industriepolitische Eingriffe in den Rundfunkmarkt vollkommen. Der bereits vor dem Zweiten Weltkrieg im europäischen Markt führenden Rundfunkgeräteindustrie gelingt es im Zuge der »Modernisierung im Wiederaufbau«, ihre führende Stellung nicht zuletzt wegen der frühen Einführung des UKW-Rundfunks wieder zu erlangen und in den sechziger Jahren stark auszubauen.

4. Das "rundfunkindustrielle Selbstbewußtsein« der Bundesrepublik kommt schließlich in der PAL-SECAM-Kontroverse voll zum Ausdruck. Trotz erheblicher innen- und außenpolitischer Bemühungen, die deutsche Rundfunkindustrie - allen voran Telefunken - zu einem Zusammengehen mit den Franzosen im Sinne eines technisch-industriellen Symbols »deutsch- 
französischer Annäherung « zu bewegen, setzen sich die PAL- und damit die marktwirtschaftlichen Interessen der deutschen Rundfunkindustrie durch. In Frankreich kann die SECAM-Propagation als Fortführung der national ausgerichteten industriepolitischen Interessen gedeutet werden. Eine zusätzliche außenpolitische »Aufladung « erhält die SECAM-Frage im Zuge der de Gaulleschen »politique de la grandeur«, in der technologische Prestigeprojekte im Sinne von »champions nationaux « zu Symbolen der französischen Modernisierung stilisiert werden.

5. Führt man sich diese strukturellen Differenzen auf den einzelnen Vergleichsebenen vor Augen, so erstaunt es kaum, daß die zentralen Akteure der Farbfernsehkontroverse auf französischer Seite im politischen, auf bundesdeutscher Seite dagegen im industriellen Bereich ausfindig $\mathrm{zu}$ machen sind. In Frankreich avanciert Informationsminister Alain Peyrefitte zur zentralen Figur der Politisierung der Farbfernsehfrage. Im Informationsministerium werden die industrie- und außenpolitischen Strategien entworfen. Als Schnittstelle zwischen rundfunkpolitischen (ORTF), industriellen (CFT/CSF) und außenpolitischen (Quai d'Orsay und Elysée Palast) Akteuren werden im Informationsministerium alle SECAM-Aktivitäten koordiniert. Ein speziell mit dieser Aufgabe beauftragter "Délégué interministériel« verkörpert die Idee planwirtschaftlicher Industriepolitik und spiegelt das technokratische Selbstbewußtsein staatlicher französischer Verwaltungseliten.

6. In der Bundesrepublik avanciert mit Walter Bruch ein »einfacher« Forschungsingenieur zum zentralen »system builder«, dem es gelingt, sukzessive die eigene Firmenleitung, die bundesdeutsche Rundfunkindustrie sowie die führenden Rundfunktechniker (IRT/FTZ) für das PAL-System zu gewinnen. Vergleicht man die finanzielle und symbolische Unterstïtzung, die das SECAM-System in Frankreich erfahren hat, mit den finanziellen Zuwendungen, die Bruch zur Entwicklung des PAL-Systems zur Verfügung standen, so mutet der Vergleich wie der Kampf Davids gegen Goliath an. Durch die geschickte Besetzung zentraler Schnittstellen im nationalen und internationalen Netzwerk gelang es Bruch jedoch, die materiellen und politischen Defizite durch informationspolitische Vorteile zu kompensieren. Persönlicher Einsatz, strategisches Operieren in wichtigen Netzwerken und der "symbolische Mehrwert « deutscher Technik verhalfen dem PAL-System schließlich zur erfolgreichen Konkurrenz mit dem finanziell und politisch hochsubventionierten SECAM-System.

In der Einleitung wurde Technik als historisch gewachsene, sozial vermittelte und symbolisch aufgeladene Kulturleistung definiert. Ziel dieser Arbeit war, die komplexen und ineinander verwobenen strukturellen Hintergründe und Akteursnetzwerke sichtbar zu machen, die gleichermaßen Ausdruck historisch gewachsener Denk- und Handlungsmuster sind (national geprägte Denkstile als Resultat spezifischer Ausbildungssysteme; diplomatische Schu- 
len; tradierte Beziehungen zwischen Staat und Industrie), das Ergebnis sozialer Interaktionen mit unterschiedlichen Handlungsoptionen und damit grundsätzlich offenem historischen Ausgang sind (Durchsetzung von technischen oder wirtschaftlichen Interessen in unterschiedlichen Machtkonstellation; sozialkonstruktivistische Dimension von Technik; Standards als Resultat von kommunikativen Strategien) und als Repräsentationen der symbolischen Bedeutung von technischen Artefakten oder Systemen fungieren (kulturelle Kapital von SECAM als »champion national«, bzw. von PAL als der »besten« Technik "Made in Germany«). Die Kombination dieser unterschiedlichen Analyseperspektiven, die jeweils unterschiedliche Einsichten in die Bedeutung institutioneller Strukturen, zentraler Akteure oder konkreter historischer Situationen ermöglichen, macht in den Augen des Autors den interpretativen Mehrwert einer politischen Kulturgeschichte der Technik aus. 
